\title{
Pyrite Oxidation in Saturated and Unsaturated Porous Media Flow: A Comparison of Alternative Mathematical Modeling Approaches
}

\author{
Tianfu $\mathrm{Xu}^{1}$, Stephen P. White ${ }^{2}$, and Karsten Pruess ${ }^{1}$ \\ ${ }^{1}$ Earth Sciences Division, Lawrence Berkeley National Laboratory, University of California, \\ Berkeley, CA 94720. \\ ${ }^{2}$ Applied Mathematics Group, Industrial Research Ltd., P.O. Box 31310, \\ Lower Hutt, New Zealand
}

\begin{abstract}
Pyrite $\left(\mathrm{FeS}_{2}\right)$ is one of the most common naturally occurring minerals that is present in many subsurface environments. It plays an important role in the genesis of enriched ore deposits through weathering reactions, is the most abundant sulfide mineral in many mine tailings, and is the primary source of acid drainage from mines and waste rock piles. The pyrite oxidation reaction serves as a prototype for oxidative weathering processes with broad significance for geoscientific, engineering, and environmental applications. Mathematical modeling of these processes is extremely challenging because aqueous concentrations of key species vary over an enormous range, oxygen inventory and supply are typically small in comparison to pyrite inventory, and chemical reactions are complex, involving kinetic control and microbial catalysis. We present the mathematical formulation of a general multi-phase advective-diffusive reactive transport model for redox processes. Two alternative implementations were made in the TOUGHREACT and TOUGH2-CHEM simulation codes which use sequential iteration and simultaneous solution, respectively. The simulators are applied to reactive consumption of pyrite in (1) saturated flow of oxidizing water, and (2) saturated-unsaturated flow in which oxygen transport occurs in both aqueous and gas phases. Geochemical evolutions predicted from
\end{abstract}


different process models are compared, and issues of numerical accuracy and efficiency are discussed.

Key words: Pyrite oxidation, Acid mine drainage, Saturated-unsaturated media, oxygen transport, Numerical approach, Reactive chemical transport.

\section{Introduction}

Pyrite oxidation generates sulfuric acid which gives rise to intense alteration of primary rock minerals, the development of secondary mineral assemblages, and the mobilization of metals. The process has been studied under laboratory and field conditions by many investigators. Lowson (1982) has reviewed the literature on abiotic chemical oxidation and Nordstrom (1982) the literature on both abiotic and biotic geochemical oxidation. More recent studies include McKibben and Barnes (1986), Ague and Brimhall (1989), Welch et al. (1990), Walter et al., (1994), Wunderly et al., (1996), Nordstrom and Alpers, (1997), Lefebvre (1995), and Lefebvre et al. (1998).

In the unsaturated zone, pyrite oxidation occurs through a complex interplay of multiphase flow and transport processes. The ultimate oxidant is atmospheric oxygen, although the actual pyrite oxidation step may involve ferric ion, $\mathrm{Fe}^{3+}$, (Lefebvre et al, 1998). In natural subsurface environments, bacterial catalysis plays an important role in the kinetics of pyrite oxidation (Kleinmann et al. 1981). The oxygen consumed during pyrite oxidation is supplied from gaseous oxygen dissolved in the aqueous phase. Dissolved oxygen is replenished by percolating oxygenated rainwater, and by dissolution of oxygen that is present in the gas-filled 
portion of the pore space. The dissolution of gaseous oxygen reduces oxygen partial pressure, as well as the total pressure of the gas phase. Gaseous oxygen is replenished by diffusion and advection in the gas phase from the land surface boundary. As will be seen below, under conditions of low liquid saturation in the unsaturated zone, gas diffusion can be a more important mechanism for oxygen supply than gas or liquid advection. Dissolution of gaseous oxygen and subsequent transport to the reactive mineral surfaces may involve diffusive transport processes on a 'local' (pore level) scale. Additional process complexities arise in fractured-porous media, where global transport of oxygen occurs primarily through a network of interconnected fractures, while oxygen may penetrate into tight matrix blocks primarily through relatively slow diffusive transport in gas and liquid phases. Depending on the spatial scale of interest, the 'kinetics' of pyrite oxidation may involve not just 'true' chemical kinetics, but may be affected by small-scale transport processes.

Redox reactions provide very severe challenges for mathematical modeling because the concentrations of important chemical species such as $\mathrm{O}_{2}(\mathrm{aq}), \mathrm{SO}_{4}{ }^{2-}$ and $\mathrm{HS}^{-}$may change by as much as 70 orders of magnitude between oxidizing and reducing conditions (Xu et al., 1998a). The purpose of the present paper is to present and partially evaluate alternative approaches for modeling redox processes in reactive flow systems. Modeling approaches for coupled processes of mass transport and chemical reactions in subsurface systems have been presented by a number of investigators (Yeh and Tripathi, 1989; Simunek and Suares, 1994; Steefel and Lasaga, 1994; Walter et al., 1994; Zysset et al., 1994; White, 1995; and Lichtner, 1996). These differ in their emphasis on accuracy and comprehensiveness of flow and transport modeling on the one hand, and chemical interactions between rocks and fluids on the other. Three major approaches have been used to couple mass transport and chemical reaction: (1) the direct substitution approach 
(DSA), which substitutes the chemical reaction equations directly into the transport equations; (2) the sequential iteration approach (SIA), which solves the transport and the reaction equations separately in a sequential manner with an iterative procedure; and (3) the sequential non-iterative approach (SNIA), which is similar to the SIA but without the iterative procedure. Owing to the enormous diversity of transport and chemical reaction phenomena, no universally accepted methodology for modeling such processes has emerged, or is likely to emerge. Instead, simulation methodology must be carefully chosen and tailored to the specific physical and chemical properties of the system being investigated, and to the objectives of the modeling study.

The organization of the paper is as follows. We begin with a description and specification of the chemical system under study, and summarize two alternative modeling approaches as implemented in the TOUGH2-CHEM (White, 1995) and TOUGHREACT (Xu et al., 1997) codes. Then we describe the fully and variably saturated test problems examined in this study. Results from both codes are compared with respect to predicted geochemical evolution, and with respect to numerical accuracy and efficiency. The paper concludes with a discussion of possibilities and limitations for modeling redox-driven reactive chemical transport in multidimensional heterogeneous field systems over extended time periods.

\section{Reaction mechanisms and kinetic rates}

Recent studies have shown reasonable agreement on pyrite oxidation rates, although it is often difficult to make a direct comparison between experiments as initial $\mathrm{pH}$, preparation 
methods, grain size, temperature, etc. may be different. Also reaction rates measured in the field may differ by orders of magnitude from those measured in the laboratory.

Another problem is determining the dominant reaction responsible for pyrite oxidation. Two candidates (see, for example, McKibbin and Barnes 1986) are

$$
\mathrm{FeS}_{2}+\frac{7}{2} \mathrm{O}_{2}+\mathrm{H}_{2} \mathrm{O} \Leftrightarrow \mathrm{Fe}^{2+}+2 \mathrm{SO}_{4}^{2-}+2 \mathrm{H}^{+}
$$

and the pair

$$
\begin{array}{r}
\mathrm{FeS}_{2}+14 \mathrm{Fe}^{3+}+8 \mathrm{H}_{2} \mathrm{O} \Leftrightarrow 15 \mathrm{Fe}^{2+}+2 \mathrm{SO}_{4}^{2-}+16 \mathrm{H}^{+} \\
\mathrm{Fe}^{2+}+\frac{1}{4} \mathrm{O}_{2}+\mathrm{H}^{+} \Leftrightarrow \mathrm{Fe}^{3+}+\frac{1}{2} \mathrm{H}_{2} \mathrm{O}
\end{array}
$$

Reaction (2) is known to be much faster than reaction (1). Nordstrom and Alpers (1997) summarized the pyrite oxidation rate constants from several studies including McKibben and Barnes (1986), Brown and Jurinak (1989), and Nicholson (1994) (cited for a pH close to 2, a $\mathrm{Fe}^{3+}$ concentration of $10^{-3} \mathrm{~mol}^{-1}$, temperature close to $25^{\circ} \mathrm{C}$, and oxygen in equilibrium with the atmosphere). The rate constants of pyrite oxidation by $\mathrm{O}_{2}$ range from $1.1 \times 10^{-10}$ to $5.3 \times 10^{-10} \mathrm{~mol}$ $\mathrm{m}^{-2} \mathrm{~s}^{-1}$ (moles of pyrite oxidation per square meter reactive surface area per second), while those by $\mathrm{Fe}^{3+}$ range from $9.6 \times 10^{-9}$ to $1.9 \times 10^{-8} \mathrm{~mol} \mathrm{~m}^{-2} \mathrm{~s}^{-1}$. Because the pyrite oxidation rate by $\mathrm{Fe}^{3+}$ is much faster than that by $\mathrm{O}_{2}$, it is important to know the oxidation rate for $\mathrm{Fe}^{2+}$ to $\mathrm{Fe}^{3+}$ according to equation (2b). Under acid conditions, the rate becomes very slow. Singer and Stumm (1968) 
reported an abiotic rate of $2.7 \times 10^{-12} \mathrm{~mol} \mathrm{l}^{-1} \mathrm{~s}^{-1}$ (moles per liter solution per second) at $\mathrm{pH}$ values below 4. After normalizing this rate in terms of square meter reactive surface area it is equal to $1.53 \times 10^{-10} \mathrm{~mol} \mathrm{~m}^{-2} \mathrm{~s}^{-1}$ using a porosity of 0.1 , a water saturation of 0.3 , and a specific surface area of $586.7 \mathrm{~m}^{2} \mathrm{~m}^{-3}$ (square meter per cubic meter medium). Such rates are considerably slower than the pyrite oxidation rate by $\mathrm{Fe}^{3+}$, hence equation (2b) would be the rate-limiting step were it not for the catalytic effect of the bacteria Thiobacillus ferrooxidans (Singer and Stumm, 1968; Nordstrom and Alpers, 1997). This effect on the oxidation of $\mathrm{Fe}^{2+}$ to $\mathrm{Fe}^{3+}$ may increase the rate by a factor of $10^{5}$ from about $2.7 \times 10^{-12} \mathrm{~mol} \mathrm{l}^{-1} \mathrm{~s}^{-1}$ to about $2.7 \times 10^{-7} \mathrm{~mol} \mathrm{l}^{-1} \mathrm{~s}^{-1}$ according to Singer and Stumm $(1968,1970)$. The catalytic effect on the oxidation rate of pyrite is not clear. Nordstrom and Alpers (1997) note that results of Olson (1991) suggest the oxidation rate of pyrite in the presence of $T$. ferrooxidans is little changed from that for the oxidation of pyrite by $\mathrm{Fe}^{3+}$. However they argue that the rate determining step is the production of $\mathrm{Fe}^{3+}$ by oxidation of $\mathrm{Fe}^{2+}(2 \mathrm{~b})$ rather than the heterogeneous reaction (2a).

Estimates of field pyrite oxidation rate cover a wide range of values. We cannot use field measurements of pyrite oxidation rates in this work, as the rate determining process is often transport of oxygen or other reactants to the reaction site. These are exactly the processes we wish to model in this work and so it is more appropriate to use the laboratory rates. The important parameter is not the pyrite oxidation rate constant but an effective rate given by the product (oxidation rate constant) $\times$ (reactive surface area). There is also great uncertainty as to the appropriate reactive surface area to use for field simulations. The effective value may be much smaller than those documented in Nordstrom and Alpers (1997). If flow is predominantly in fractures, then only a small portion of the pyrite will be exposed to oxygenated groundwater. Field pyrite oxidation rates are also complicated by many other factors such as microbial growth 
kinetics, organic compounds, secondary mineral formation, and climatic patterns, which are beyond the scope of this paper.

Regardless of whether pyrite oxidation is dominated by reaction (1) or (2), oxygen availability is a very important factor. Reaction (1) directly uses oxygen, while (2) involves oxygen only indirectly. Extensive oxidation is limited to the unsaturated zone, where gas phase $\mathrm{O}_{2}$ transport may be rapid. As aqueous phase oxygen is depleted through reaction with pyrite, it is replenished by dissolution from the gas phase,

$$
\mathrm{O}_{2}(\mathrm{~g}) \Leftrightarrow \mathrm{O}_{2}(\mathrm{aq})
$$

and by diffusive transport from the atmospheric boundary at the land surface. As a result, the water can have high concentrations of $\mathrm{Fe}^{2+}, \mathrm{SO}_{4}{ }^{2-}$, and $\mathrm{H}^{+}$. All reactions considered are listed in Table 1. Aqueous dissociation and gas dissolution are assumed to proceed according to local equilibrium. Pyrite oxidation is subject to kinetic control.

Table 1. List of reactions involved in pyrite oxidation. Thermodynamic equilibrium constants are from the EQ3/6 database (Wolery, 1992).

Reaction

$\log _{10} \mathrm{~K}$ at $25^{\circ} \mathrm{C}$ 


$$
\begin{array}{lc}
\mathrm{O}_{2}(\mathrm{~g})=\mathrm{O}_{2}(\mathrm{aq}) & -2.898 \\
\text { pyrite }\left(\mathrm{FeS}_{2}\right)+7 / 2 \mathrm{O}_{2}(\mathrm{aq})+\mathrm{H}_{2} \mathrm{O}=2 \mathrm{H}^{+}+2 \mathrm{SO}_{4}^{2-}+\mathrm{Fe}^{2+} & 217.4 \\
& 138.32 \\
\mathrm{HS}^{-}+2 \mathrm{O}_{2}(\mathrm{aq})=\mathrm{H}^{+}+\mathrm{SO}_{4}^{2-} & 131.33 \\
\mathrm{H}_{2} \mathrm{~S}(\mathrm{aq})+2 \mathrm{O}_{2}(\mathrm{aq})=2 \mathrm{H}^{+}+\mathrm{SO}_{4}^{2-} & 8.475 \\
\mathrm{Fe}^{2+}+1 / 4 \mathrm{O}_{2}(\mathrm{aq})+\mathrm{H}^{+}=\mathrm{Fe}^{3+}+1 / 2 \mathrm{H}_{2} \mathrm{O} & 13.995 \\
\mathrm{OH}^{-}+\mathrm{H}^{+}=\mathrm{H}_{2} \mathrm{O} & -1.979 \\
\mathrm{HSO}_{4}^{-}=\mathrm{H}^{+}+\mathrm{SO}_{4}^{2-} & -2.2 \\
\mathrm{FeSO}_{4}(\mathrm{aq})=\mathrm{SO}_{4}^{2-}+\mathrm{Fe}^{2+} &
\end{array}
$$

Lasaga et al. (1994) give the following general expression to describe the kinetic reaction rate for mineral dissolution or precipitation

$$
\mathrm{r}=\mathrm{Aka}_{\mathrm{H}+}^{\mathrm{n}}\left(1-\Omega^{\theta}\right)^{\eta}
$$

where $\mathrm{k}$ is the rate constant (moles per unit mineral surface area and unit time) which is a function of temperature, $\mathrm{A}$ is the specific reactive surface area per unit liquid volume, $\Omega$ is the mineral saturation ratio (i.e., the ratio between the ion activity product and the equilibrium constant). The parameters $\theta$ and $\eta$ must be determined from experiments; in this work, they are taken to be one. The term $a_{H^{+}}^{n}$ accounts for the catalytic effect of $\mathrm{H}^{+}$where the value of $\mathrm{n}$ is determined experimentally; in this simulation this term is not considered (i.e., $a_{\mathrm{H}^{+}}^{\mathrm{n}}=1$ ). We use a rate expression based on (4) but include a dependence on liquid saturation in variably saturated media. The rate given in (4) is multiplied by a function of liquid saturation $\mathrm{f}\left(\mathrm{S}_{1}\right)$ (see Figure 1) derived from laboratory measurements by Welch et al. (1990). The fractional factor $\mathrm{f}\left(\mathrm{S}_{1}\right)$ accounts for the effective sizes on the mineral pyrite surface that are actively available to adsorb 
and chemically bond with aqueous species. It should be pointed out that $f\left(S_{1}\right)$ is a property of the medium and may vary in space.

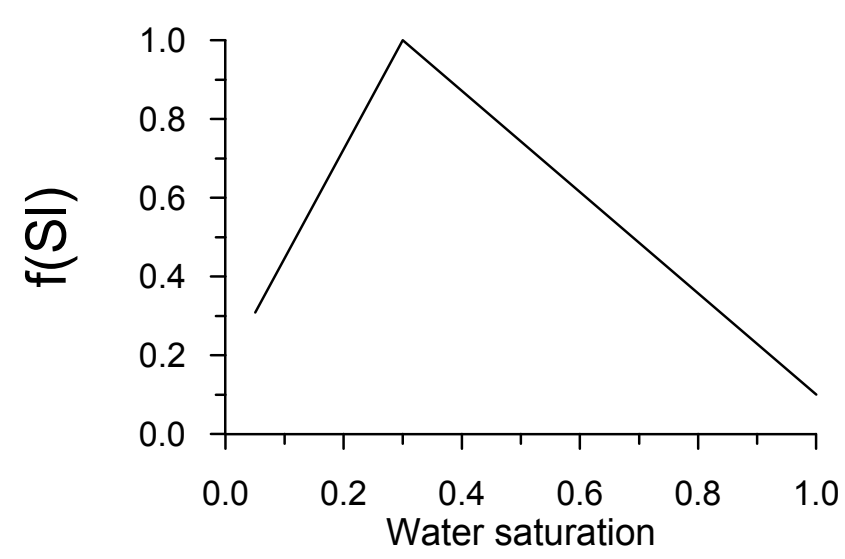

Figure 1. Liquid saturation dependent factor used for kinetic rate expression (Eq. 4).

\section{Mathematical model and numerical approaches}

\subsection{Governing equations}

Two types of primary governing equations are required to be solved, non-isothermal multiphase flow and multi-component reactive chemical transport.

Non-isothermal multi-phase flow consists of fluid flow in both liquid and gas phases, and heat transport. The processes occurring in multi-phase flow were discussed in detail by Pruess (1987, 1991). In this work the major assumptions made are: (1) air is treated as an ideal gas, and additivity of partial pressure is assumed for air/vapor mixtures; (2) porosity and permeability change from mineral dissolution/precipitation is not considered; (3) concentration changes of aqueous and gaseous chemical species do not influence fluid thermodynamic properties such as 
density and viscosity; and (4) heat generation due to chemical reactions such as pyrite oxidation is neglected. Although in this study we only use isothermal condition (constant temperature, 25 ${ }^{\circ} \mathrm{C}$ ), for general our model can be applied to non-isothermal conditions. The conservation equations for multi-phase flow of water, air and heat can be written as

for water

$$
\frac{\partial}{\partial t}\left[\phi\left(S_{1} \rho_{1} X_{w l}+S_{g} \rho_{g} X_{w g}\right)\right]=-\nabla \cdot\left(X_{w l} \rho_{1} \mathbf{u}_{1}+X_{w g} \rho_{g} \mathbf{u}_{g}\right)+q_{w}
$$

for air

$$
\frac{\partial}{\partial \mathrm{t}}\left[\phi\left(\mathrm{S}_{1} \rho_{1} \mathrm{X}_{\mathrm{al}}+\mathrm{S}_{\mathrm{g}} \rho_{\mathrm{g}} \mathrm{X}_{\mathrm{ag}}\right)\right]=-\nabla \cdot\left(\mathrm{X}_{\mathrm{al}} \rho_{\mathrm{l}} \mathbf{u}_{1}+\mathrm{X}_{\mathrm{ag}} \rho_{\mathrm{g}} \mathbf{u}_{\mathrm{g}}\right)+\mathrm{q}_{\mathrm{a}}
$$

for heat

$$
\frac{\partial}{\partial \mathrm{t}}\left[\phi\left(\mathrm{S}_{1} \rho_{1} \mathrm{U}_{1}+\mathrm{S}_{\mathrm{g}} \rho_{\mathrm{g}} \mathrm{U}_{\mathrm{g}}\right)+(1-\phi) \rho_{\mathrm{s}} \mathrm{U}_{\mathrm{s}}\right]=-\nabla \cdot\left[\sum_{\beta=1, \mathrm{~g}} \mathrm{~h}_{\beta} \rho_{\beta} \mathbf{u}_{\beta}-\lambda \nabla \mathrm{T}\right]+\mathrm{q}_{\mathrm{H}}
$$

where

$$
\mathbf{u}_{\beta}=-\mathrm{k} \frac{\mathrm{k}_{\mathrm{r} \beta}}{\mu_{\beta}}\left(\nabla \mathrm{P}_{\beta}-\rho_{\beta} \mathbf{g}\right) \quad \beta=1, \mathrm{~g}
$$

is volumetric flux (Darcy velocity), the subscripts 1, g, and s indicate the liquid, gas and solid phases respectively; the subscripts $\mathrm{w}$, a, and $\mathrm{H}$ indicate water, air and heat respectively; $\mathrm{S}_{\beta}$ is 
the saturation of phase $\beta ; \phi$ the porosity; $\rho_{\beta}$ the phase density; $\mu_{\beta}$ the phase viscosity; $X_{w \beta}$ is mass fraction of water in phase $\beta$; $\mathrm{k}$ is the permeability, $\mathrm{k}_{\mathrm{r} \beta}$ is the relative permeability for phase $\beta ; \mathrm{P}_{\beta}$ is the pressure in phase $\beta ; \mathbf{g}$ is the gravitational acceleration; $\mathbf{u}_{\beta}$ is Darcy velocity for phase $\beta ; U_{\beta}$ is internal energy of phase $\beta ; h_{\beta}$ is the specific enthalpy of phase $\beta$; $\lambda$ is the heat conductivity of the rock-fluid mixture; $T$ is the temperature; and $\mathrm{q}_{\mathrm{w}}, \mathrm{q}_{\mathrm{a}}, \mathrm{q}_{\mathrm{H}}$ are source/sink terms for water, air and heat, respectively. The non-isothermal multiphase flow equations must be complemented with constitutive relationships that express all parameters as functions of thermodynamic variables. These expressions are given by Pruess (1987).

Multi-component reactive chemical transport. Aqueous (dissolved) species are subject to transport in the liquid phase, as well as to local chemical interactions with other aqueous species, and solid and gaseous species. Gaseous species transport in the gas phase and react with aqueous species. Solid species only participate in local chemical reactions. Based on mass conservation, the transport equations for chemical components present in the liquid and gas phases can be expressed as

in the liquid phase

$$
\frac{\partial}{\partial t}\left(\phi S_{1} C_{j 1}\right)=-\nabla \cdot\left(u_{1} C_{j 1}-D_{1} \nabla C_{j 1}\right)+q_{j 1}+r_{j s}+r_{j g} \quad j=1,2, \ldots, N_{1}
$$

in the gas phase 


$$
\frac{\partial}{\partial t}\left(\phi S_{g} C_{j g}\right)=-\nabla \cdot\left(\mathbf{u}_{g} C_{j g}-D_{g} \nabla C_{j g}\right)+q_{j g}-r_{j g} \quad j=1,2, \ldots, N_{g}
$$

where subscript $\mathrm{j}$ is the component index; $\mathrm{N}_{1}$ and $\mathrm{N}_{\mathrm{g}}$ are the numbers of chemical components present in the liquid and gas phases; $C_{j \beta}$ is the concentration of component $j$ in phase $\beta$ (=1, or g); $D_{\beta}$ is the molecular diffusion coefficient in phase $\beta$ (=1 or $g$ ) and assumed to be not speciesdependent; $\mathrm{q}_{\mathrm{j} \beta}$ is external source/sink rate for component $\mathrm{j}$ in phase $\beta(=1$ or $g) ; r_{\mathrm{js}}$ is the mass transfer rate from the solid to the liquid phase; and $r_{j g}$ is the gas dissolution rate.

Assuming the gas phase acts as an ideal gas, gaseous concentrations (in moles per liter) can be calculated from their partial pressures using

$$
C_{j g}=\frac{10^{2}}{R T_{s}} P_{j g}=\kappa P_{j g}
$$

where $\mathrm{P}_{\mathrm{jg}}$ is the partial pressure (in bar) of component $\mathrm{j}, \mathrm{R}$ is the gas constant $\left(8.314 \mathrm{~J} \cdot \mathrm{mol}^{-1} \cdot \mathrm{K}^{-}\right.$ ${ }^{1}$ ), $\mathrm{T}_{\mathrm{s}}$ is the absolute temperature, and $\mathrm{C}_{\mathrm{jg}}$ is the concentration (in moles/liter) of component $\mathrm{j}$ in the gas phase. For use in TOUGHREACT, by substituting (11) into (10), the transport equations for chemical components present in the gas phase can be written in terms of partial pressures

$$
\frac{\partial}{\partial t}\left(\phi S_{g} \kappa P_{j g}\right)=-\nabla \cdot\left[\kappa\left(\mathbf{u}_{g} P_{j g}-D_{g} \nabla P_{j g}\right)\right]+q_{j g}-r_{j g} \quad j=1,2, \ldots, N_{g}
$$


Terms $r_{j s}$ and $r_{j g}$ in (9) and (12) are functions of dissolved concentrations which render the reactive chemical transport equations highly nonlinear. TOUGH2-CHEM incorporates equation (10) directly into the numerical equations and need not assume perfect gas behavior or Henry's law (although $t$ does for this work). These primary governing equations must be complemented with constitutive chemical relationships. These relationships, including mass-balance equations for equilibrium reactions and rate expressions for kinetic reactions, are given in Xu et al. (1997).

\subsection{Numerical approaches}

Two alternative modeling approaches as implemented in the TOUGH2-CHEM (White, 1995) and TOUGHREACT (Xu et al., 1997) codes are used. Both codes are based on the framework of the non-isothermal multi-phase flow simulator TOUGH2 (Pruess 1991). The numerical solution of the multi-phase flow and reactive chemical transport equations employs space discretization by means of integral finite differences (Narasimhan and Witherspoon, 1976) and fully implicit first-order finite differences in time. However, the coupled approach between flow and reactive transport is different in the two codes. TOUGH2-CHEM employs a fully coupled approach where all flow and reactive transport equations are solved simultaneously. TOUGHREACT uses a sequential iteration approach similar to Yeh and Tripathi (1989), Simunek and Suares ( 1994), Steefel and Lasaga (1994), Walter et al (1994), and Lichtner (1996). The multi-phase flow and reactive chemical transport equations are solved sequentially. After solution of the flow equations, the fluid velocities and phase saturations are used for chemical transport simulation. The chemical transport is solved on a component basis by taking chemical reaction source/sink terms from the previous reaction iteration. The resulting 
concentrations obtained from the transport are substituted into the chemical reaction model. The chemical reactions are solved on a grid-block basis. The chemical transport and reactions are iteratively solved until convergence.

TOUGHREACT can work with two different fluid flow modules, known as EOS9 and EOS3. Using EOS9, only saturated-unsaturated liquid phase flow is considered (Richards' equation). In this case only the oxygen diffusion process can be considered for gaseous species transport. Using EOS3, the full non-isothermal multi-phase flow equations (for liquid, gas and heat) are solved. The dissolution of gaseous oxygen induced by pyrite oxidation reduces oxygen partial pressure, as well as the total pressure of the gas phase. As a result, the gas flow is modified, then the liquid phase flow. This reaction effect on the fluid flow is not considered, although advection and diffusion are considered for oxygen transport processes. On the other hand, TOUGH2-CHEM solves the multi-component chemical transport simultaneously with the heat and mass flow problem so that equations of flow and multi-component transport are fully coupled and the reaction effect on the fluid flow is taken into account. This coupling of flow to chemical reaction is not significant in the examples presented in this paper, however when fluid flow and chemical reactions are strongly coupled, such as when boiling takes place in geothermal reservoirs, this may be essential.

Due to a large inventory of the solid mineral (pyrite) and the comparatively small concentrations of aqueous reactants such as dissolved oxygen, the mineral (pyrite) dissolution requires the order of $10^{4}-10^{5}$ pore volumes of fluid. For these reasons, a number of numerical improvements for convergence and efficiency, such as modification of the Jacobian matrix, use of quasi-stationary approximation, and automatic time stepping were made (see $\mathrm{Xu}$ et al., 1998a). 


\section{Flow systems}

Two one-dimensional flow systems were modeled. In the first example (Figure 2), a onedimensional horizontal porous column $2 \mathrm{~m}$ long with a cross-sectional area of $1 \mathrm{~m}^{2}$ contains the mineral pyrite; at the left boundary infiltration water is injected at $0.02 \mathrm{~m} \mathrm{day}^{-1}$ and is withdrawn from the right boundary at the same rate. Porosity of the column is 0.4 which, with the prescribed injection rate, leads to a pore velocity of $0.05 \mathrm{~m} \mathrm{day}^{-1}$. The column is discretized with a grid spacing of $0.05 \mathrm{~m}$.

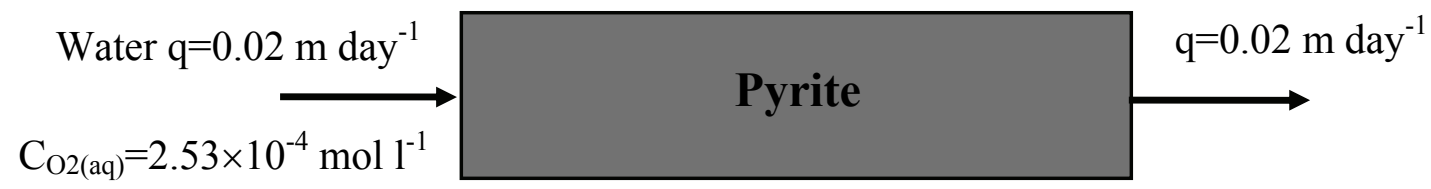

Figure 2. Schematic representation of the 1-D horizontal saturated flow system used for pyrite oxidation.

The second example models a vertical column extending from the atmosphere through an unsaturated and a saturated zone and extending below the water table (see Figure 3). Oxygen is supplied to the top of the column as a dissolved species in infiltrating rainwaters and may also be transported by gaseous diffusion and advection from the land surface. Because TOUGH2-CHEM includes the a coupling between the gas (and liquid) phase flows and chemical reaction it is not possible to solve identical problems with the two codes when the gas phase is included. For the unsaturated example TOUGH2-CHEM must include an extra component, nitrogen, to correctly 
model the gas phase. The initial flow conditions are set by specifying the rate of water infiltration into the top of the model $\left(0.07 \mathrm{~m} \mathrm{yr}^{-1}\right.$, variations in infiltration is not considered in this study) and a constant pressure of 3.5 bar at the bottom. The steady state water saturations obtained by ignoring chemical reactions are used as initial conditions for the calculation of reactive chemical transport. Parameters for this unsaturated-saturated medium are listed in Table 2. The steady-state water saturation profile is given in Figure 4.

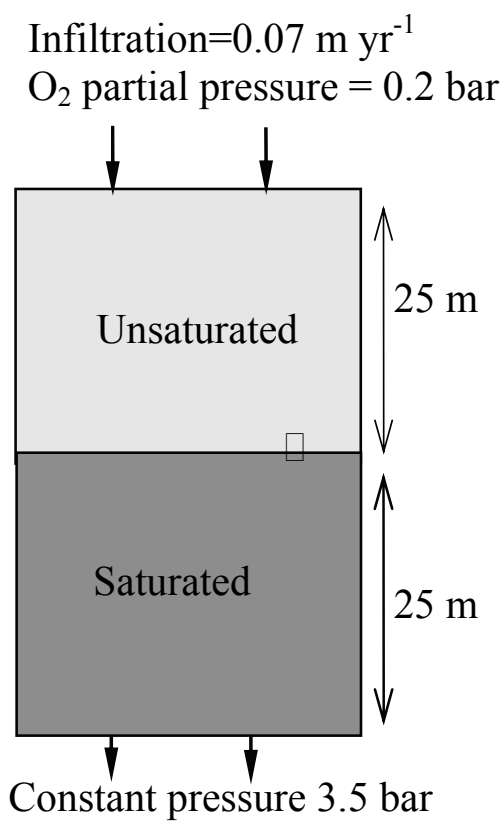

Figure 3. Schematic representation of the unsaturated-saturated flow system used for pyrite oxidation. The system can be considered as part of mine tailings or waste pile, or as a mineralized site that contains the mineral pyrite $\left(\mathrm{FeS}_{2}\right)$. 


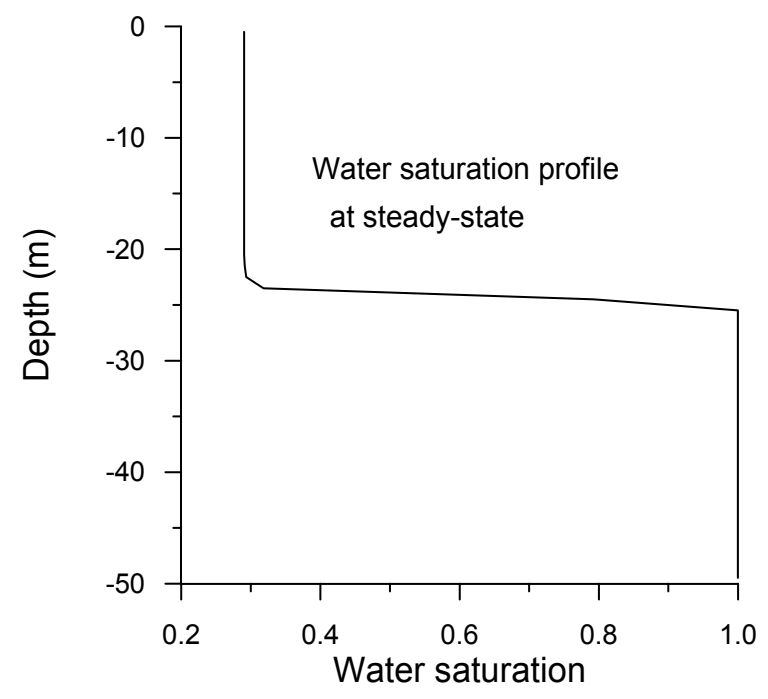

Figure 4. The steady-state water saturation distribution along the unsaturated-saturated medium.

Table 2. Physical and chemical parameters used for the unsaturated-saturated flow system.

\begin{tabular}{|c|c|}
\hline Parameter & Value \\
\hline Infiltration $\left(\mathrm{m} \mathrm{yr}^{-1}\right)$ & 0.07 \\
\hline Depth (m) & 50 \\
\hline Grid size (m) & 1 \\
\hline $\mathrm{O}_{2}$ partial pressure at the land surface (bar) & 0.2 \\
\hline Permeability $\left(\mathrm{m}^{2}\right)$ & $7 \times 10^{-12}$ \\
\hline gas $\mathrm{O}_{2}$ diffusivity $\left(\mathrm{m}^{2} \mathrm{~s}^{-1}\right)$ & $4.4 \times 10^{-5}$ \\
\hline Tortuosity & 0.1 \\
\hline Porosity & 0.1 \\
\hline \multicolumn{2}{|l|}{$\begin{array}{l}\text { Relative permeability and capillary Pressure } \\
\text { (van Genuchten curves, 1980): }\end{array}$} \\
\hline$\lambda$ & 0.457 \\
\hline $\mathrm{S}_{\mathrm{lr}}$ & 0.05 \\
\hline $\mathrm{S}_{\mathrm{ls}}$ & 1.0 \\
\hline $\mathrm{P}_{0}(\mathrm{~Pa})$ & $1.96 \times 10^{3}$ \\
\hline Kinetic rate constant, $\mathrm{k},\left(\mathrm{mol} \mathrm{m} \mathrm{s}^{-2}\right)$ & $2 \times 10^{-13}-2 \times 10^{-10}$ \\
\hline Specific surface area $\left(\mathrm{m}^{2} \mathrm{~m}^{-3}\right)$ & 58.67 \\
\hline
\end{tabular}

For both flow systems, the initial water composition corresponds to a dilute reducing water with aqueous oxygen concentration, $\mathrm{c}_{\mathrm{O}_{2}(\mathrm{aq})}$, of $1.0 \times 10^{-70} \mathrm{~mol} \mathrm{l}^{-1}$. The infiltration water 
compositions correspond to a dilute oxidizing water with $\mathrm{c}_{\mathrm{O}_{2}(\mathrm{aq})}=2.53 \times 10^{-4}$ which is at equilibrium with an atmospheric $\mathrm{O}_{2}$ partial pressure of 0.2 bar. Initial pyrite abundance is $9 \%$ by volume.

Five cases were simulated for the two flow systems that involved different combinations of chemical transport by liquid advection, oxygen gas transport by diffusion and advection, and pyrite oxidation controlled by equilibrium or kinetics. These cases are summarized in Table 3 , in order of increasing complexity.

Table 3. List of simulation cases with different combinations of flow system, transport process, and reaction type (equilibrium/kinetics). Symbol k represents the kinetic rate constant (units: mol $\left.\mathrm{m}^{-2} \mathrm{~s}^{-1}\right)$

\begin{tabular}{|c|c|c|c|}
\hline Flow & $\begin{array}{l}\text { Transport process } \\
\text { Pyrite oxidation (equilibrium } \\
\text { or kinetics) }\end{array}$ & Case & Codes used \\
\hline \multirow{6}{*}{$\begin{array}{l}\text { Fully saturated } \\
\text { Unsaturated- } \\
\text { saturated }\end{array}$} & $\begin{array}{l}\text { Aqueous advection } \\
\text { Equilibrium }\end{array}$ & 1 & Both \\
\hline & Aqueous advection & & \\
\hline & Equilibrium & 2 & Both \\
\hline & Kinetics $\left(\mathrm{k}=2 \times 10^{-13}, 2 \times 10^{-10}\right)$ & 3 & Both \\
\hline & $\begin{array}{l}\text { Aqueous advection and gas diffusion } \\
\text { Kinetics }\left(\mathrm{k}=2 \times 10^{-11}, 2 \times 10^{-10}\right) \\
\text { Aqueous advection, gas diffusion and } \\
\text { advection }\end{array}$ & 4 & TOUGHREACT \\
\hline & Kinetics $\left(\mathrm{k}=2 \times 10^{-11}, 2 \times 10^{-10}\right)$ & 5 & TOUGH2-CHEM \\
\hline
\end{tabular}




\section{Results}

\subsection{Horizontal saturated medium (Case 1)}

This is a relatively simple case for which the gross behaviour of the system can be determined without detailed calculation. Thus it provides a check on the simulation codes as it allows comparison of calculated dissolution front speeds with theory, and a check on mass conservation. Pyrite oxidative dissolution occurs only in the first grid block, and the $\mathrm{O}_{2}(\mathrm{aq})$ is consumed completely at this location. Dissolution of one mole of pyrite consumes 3.5 moles of aqueous $\mathrm{O}_{2}(\mathrm{aq})$, and creates 2 moles of $\mathrm{H}^{+}, 2$ moles of $\mathrm{SO}_{4}{ }^{2-}$, and 1 mole of $\mathrm{Fe}^{2+}$. Consequently, total dissolved $\mathrm{S}$ and $\mathrm{Fe}$ concentrations increase and $\mathrm{pH}$ decreases. After one day (note that time in days is equivalent to grid block pore volume, since it takes one day to move one grid block with pore velocity $=0.05 \mathrm{~m} \mathrm{day}^{-1}$ and the grid spacing $\left.=0.05 \mathrm{~m}\right)$, a quasi-stationary state (QSS, Lichtner, 1988) is reached. Dissolved concentrations remain constant along the entire column with the following values: $10^{-64.86} \mathrm{~mol}^{-1}$ for aqueous $\mathrm{O}_{2}, 1.44 \times 10^{-4}$ for total dissolved $\mathrm{S}, 7.2 \times 10^{-}$ ${ }^{5}$ for $\mathrm{Fe}$, and 3.86 for $\mathrm{pH}$. The $\mathrm{pH}$ evolution during the early transient period in the first grid block is presented in Figure 5. For this QSS, pyrite abundance in the first block decreases at a constant rate of $2.53 \times 10^{-4} \mathrm{yr}^{-1}$ by volume, which equals 0.54 moles per year. Pyrite initially has a volume fraction of $9 \%$, corresponding to 188 moles per grid block. It requires $356 \mathrm{yr}$ to dissolve all the pyrite in a grid block. The solution is entirely buffered by pyrite. The retardation factor for the oxidative dissolution front depends on the initial pyrite abundance, and is: $354 \times 365=129940$. The total amount of aqueous $\mathrm{O}_{2}$ injected during a one year period is: $2.53 \times 10^{-}$

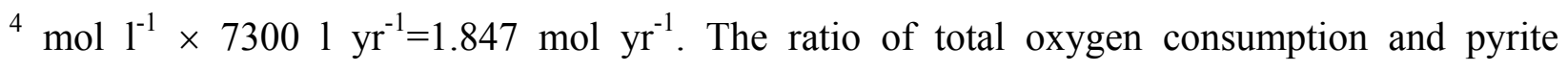
dissolution obtained in the simulation is: $1.847 / 0.54=3.42$, which is very close to the 
stoichiometric coefficient (3.5) in the pyrite oxidation reaction (1). This suggests that most of the oxygen is consumed by pyrite oxidation.

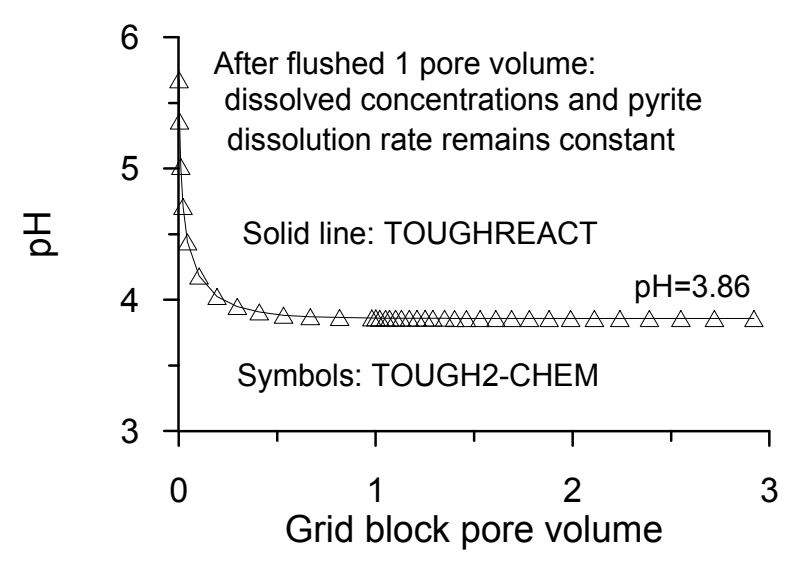

Figure 5. $\mathrm{pH}$ evolution during the early transient period (note that grid block pore volume equals time in days) in the first grid block for the horizontal saturated column.

\subsection{Unsaturated-saturated medium}

\section{Case 2 (aqueous advection and equilibrium pyrite oxidation)}

Pyrite oxidation and dissolution takes place only in the topmost first grid block, and aqueous oxygen is consumed completely. The chemical evolution is similar to case 1 . However, the transient period lasts much longer than in case 1 because of the low infiltration rate of $0.07 \mathrm{~m}$ $\mathrm{yr}^{-1}\left(7.3 \mathrm{~m} \mathrm{yr}^{-1}\right.$ in case 1$)$ and larger grid spacing (1 m vs. $\left.0.05 \mathrm{~m}\right)$. After approximately $150 \mathrm{yr}$, a quasi-stationary state is reached throughout the entire flow domain. The final $\mathrm{pH}$ and dissolved component concentrations are the same as those of case 1 (see Figure 6). 


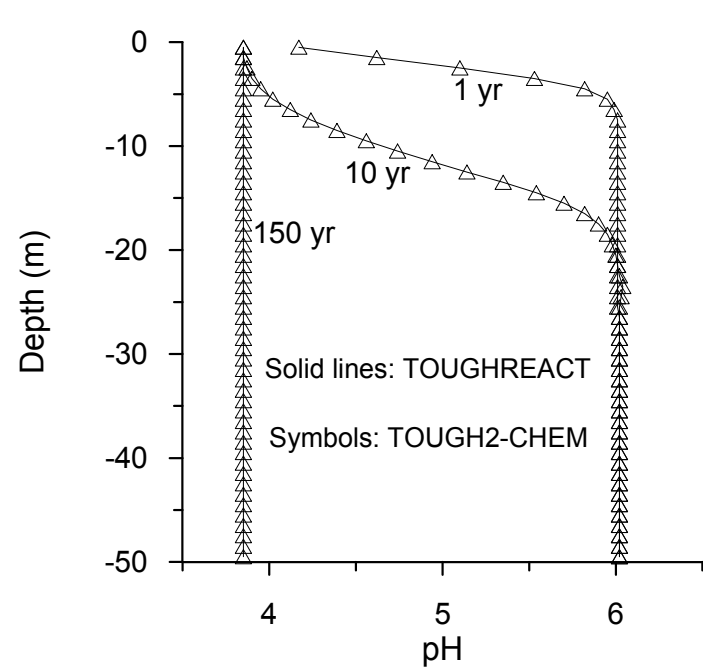

(a)

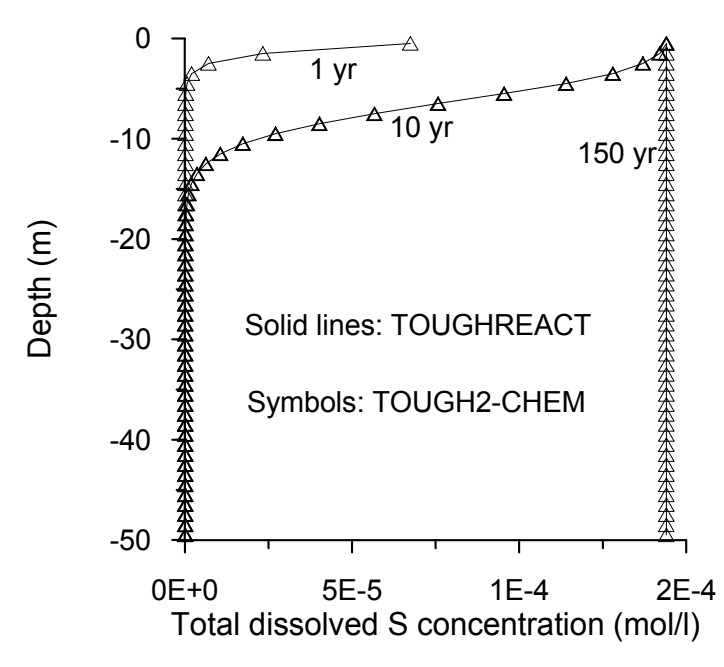

(b)

Figure 6. $\mathrm{pH}$ and dissolved concentrations at different times for case 2 (unsaturated-saturated flow, aqueous advection, and equilibrium pyrite oxidation). Total dissolved Fe concentration equals half of $\mathrm{S}$ according to the stoichiometric coefficients of pyrite $\left(\mathrm{FeS}_{2}\right)$. Case 3 results (obtained with a rate constant of $\mathrm{k}=2 \times 10^{-10} \mathrm{~mol} \mathrm{~m}^{-2} \mathrm{~s}^{-1}$ ) are indistinguishable from the equilibrium case.

\section{Case 3 (aqueous advection and kinetic pyrite oxidation)}

We first used a rate constant of $\mathrm{k}=2 \times 10^{-10} \mathrm{~mol} \mathrm{~m}^{-2} \mathrm{~s}^{-1}$. The result is the same as for the equilibrium case 2 (Figure 6), indicating that the reaction rate is limited by oxygen supply, not chemical kinetics. As mentioned above, field kinetic rate constant covers a wide range of values. To illustrate a kinetically-controlled process, we reduced the rate constant by three orders of magnitude to $\mathrm{k}=2 \times 10^{-13} \mathrm{~mol} \mathrm{~m} \mathrm{~m}^{-2}$. The result is presented in Figure 7 . We can observe a step change in $\mathrm{pH}$ from Figure $7 \mathrm{~b}$. This may be explained from the reaction processes taking place in the system. Pyrite is first oxidized creating $\mathrm{H}^{+}$and $\mathrm{Fe}^{2+}$, and consuming $\mathrm{O}_{2}(\mathrm{aq}) . \mathrm{Fe}^{2+}$ is oxidized to $\mathrm{Fe}^{3+}$ by the excess $\mathrm{O}_{2}(\mathrm{aq})$, and the ratio $\mathrm{Fe}^{2+} / \mathrm{Fe}^{3+}$ is controlled by the $\mathrm{O}_{2}(\mathrm{aq})$ concentration. 
Then aqueous species such as $\mathrm{O}_{2}(\mathrm{aq}), \mathrm{H}^{+}, \mathrm{Fe}^{2+}$, and $\mathrm{Fe}^{3+}$ are transported downward. At approximately $14 \mathrm{~m}$ depth $\mathrm{O}_{2}(\mathrm{aq})$ becomes depleted, and the reaction: $4 \mathrm{Fe}^{2+}+\mathrm{O}_{2}(\mathrm{aq})+$ $4 \mathrm{H}^{+}=4 \mathrm{Fe}^{3+}+2 \mathrm{H}_{2} \mathrm{O}$ is driven to the left-hand side. This reaction provides both $\mathrm{H}^{+}$to lower the $\mathrm{pH}$ and $\mathrm{O}_{2}$ (aq) to oxidize some more pyrite and lower the $\mathrm{pH}$ further. Because we treat the aqueous reactions as local equilibrium, almost all the $\mathrm{Fe}^{3+}$ is reacted in a single grid block and there is a step change in $\mathrm{pH}$. Figure 8 shows the concentration distribution of $\mathrm{Fe}^{2+}$ and $\mathrm{Fe}^{3+}$ obtained with the code TOUGHREACT. We can see that in the top 13 blocks $\mathrm{Fe}^{3+}$ is dominant, at the $14^{\text {th }}$ grid block, $\mathrm{Fe}^{3+}$ is dramatically reduced and $\mathrm{Fe}^{2+}$ becomes dominant. From Figure 7 we can see that results from both codes agree very well. 


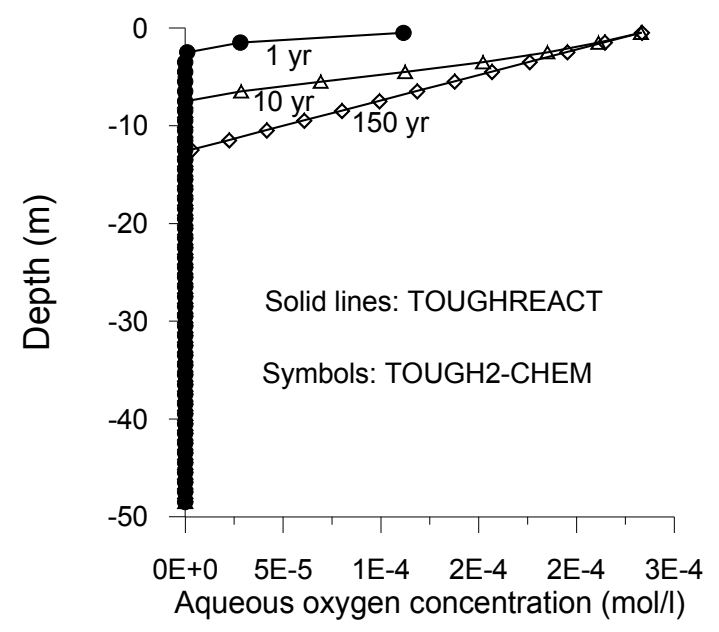

(a)

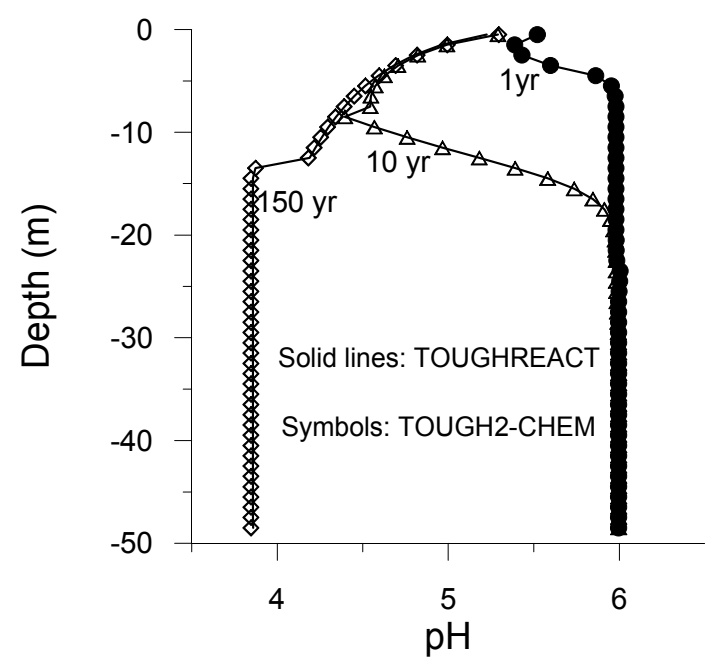

(b)

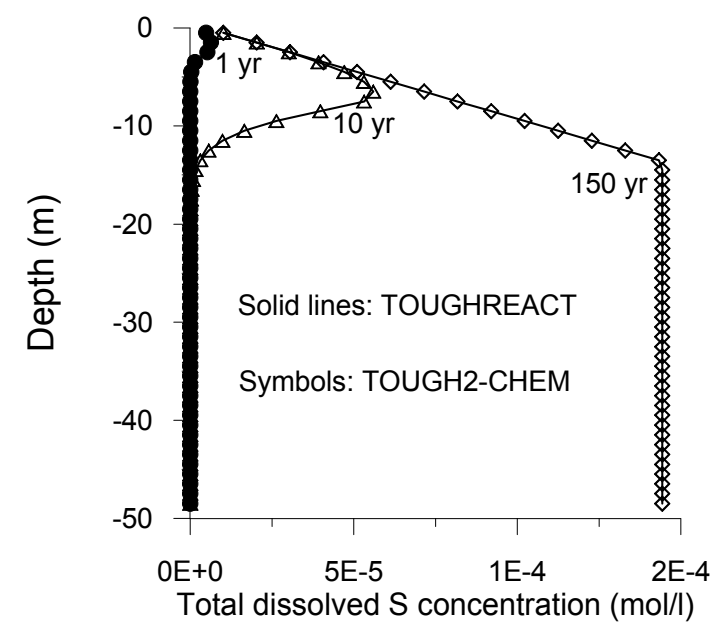

(c)

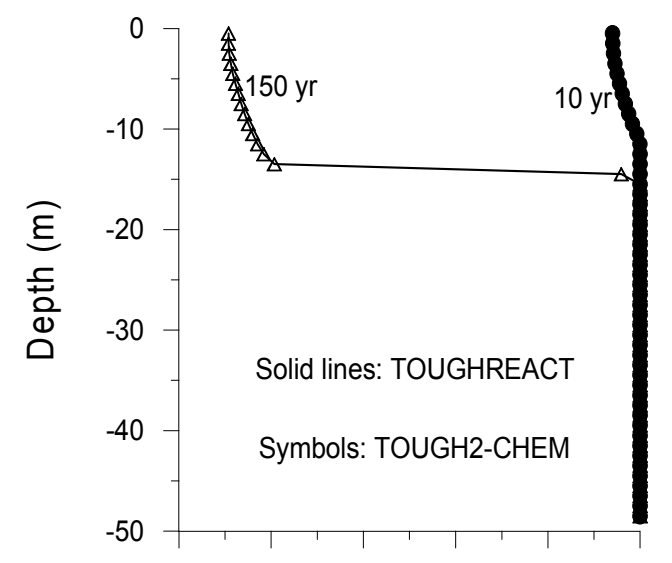

$\begin{array}{llllll}-3 E-3 & -2 E-3 & -2 E-3 & -1 E-3 & -5 E-4 & 0 E+0\end{array}$

Change of pyrite abundance (in vol. fraction \%)

(d) 
Figure 7. Aqueous oxygen, $\mathrm{pH}$, total dissolved $\mathrm{S}$ and change of pyrite abundance after $150 \mathrm{yr}$ (steady-state) considering only chemical advective transport in the liquid phase (case 3). Kinetic rate constant is reduced from $\mathrm{k}=2 \times 10^{-10}$ to $2 \times 10^{-13} \mathrm{~mol} \mathrm{~m}^{-2} \mathrm{~s}^{-1}$. Change of pyrite abundance is expressed as change in pyrite volume per unit medium volume (pyrite density $=4.177 \times 10^{4} \mathrm{~mol} \mathrm{~m}^{-}$ $\left.{ }^{3}\right)$

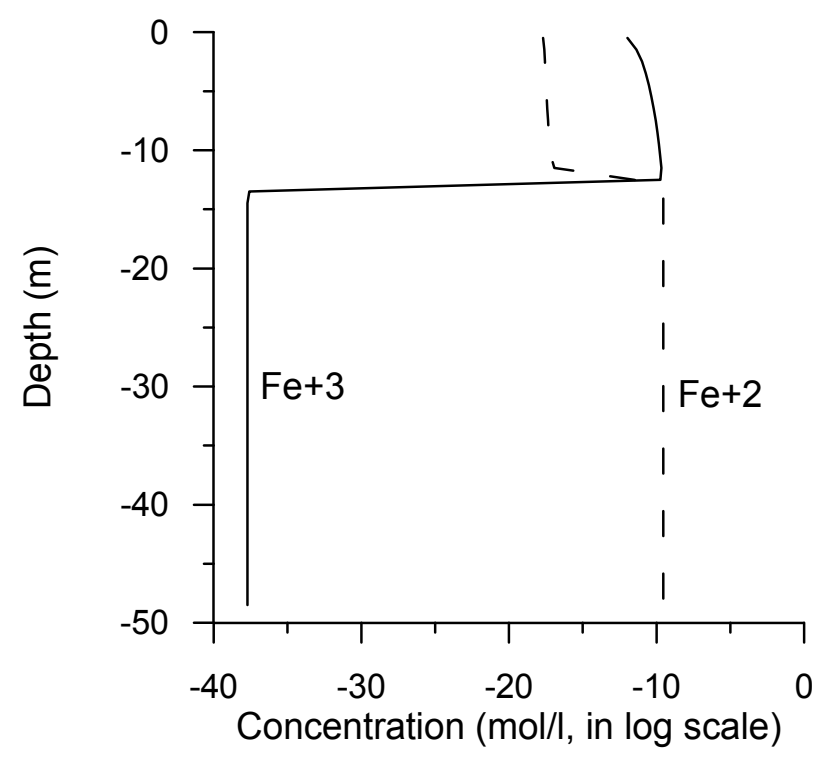

Figure 8. Concentration distribution of species $\mathrm{Fe}^{2+}$ and $\mathrm{Fe}^{3+}$ after $150 \mathrm{yr}$ (steady-state) for case 3 with a kinetic rate constant of $\mathrm{k}=2 \times 10^{-13} \mathrm{~mol} \mathrm{~m}^{-2} \mathrm{~s}^{-1}$. The results are obtained with TOUGHREACT.

Cases 4 and 5 (aqueous advection, gaseous transport, and kinetic pyrite oxidation)

The TOUGHREACT calculation includes oxygen diffusion in the gas phase in addition to the processes considered in case 3. Using an active gas phase in TOUGH2-CHEM not only invokes oxygen diffusion in the gas phase, but also includes an overall advective gas flow, in response to reduction of gas phase pressures from oxygen consumption. Because of these slightly different process descriptions, some differences are expected between cases 4 and 5 . 
Results for a rate constant of $\mathrm{k}=2 \times 10^{-10} \mathrm{~mol} \mathrm{~m}^{-2} \mathrm{~s}^{-1}$ are shown in Figure 9. Comparing with results that did not include gaseous transport (case 3, Figure 6), it is seen that the $\mathrm{pH}$ drops much more rapidly to lower values, and total dissolved $\mathrm{S}$ concentrations are several orders of magnitude larger. This indicates that gas diffusion provides a much stronger mechanism for oxygen supply than aqueous advection. Results for a tenfold smaller kinetic rate constant $\left(\mathrm{k}=2 \times 10^{-11} \mathrm{~mol} \mathrm{~m}^{-2} \mathrm{~s}^{-1}\right)$ shown in Figure 10 demonstrate that gaseous oxygen supply maintains aqueous oxygen concentrations at high levels throughout the unsaturated zone. Quasi-stationary concentrations of the dissolved $\mathrm{S}$ at $\mathrm{t}=150 \mathrm{yr}$ have similar shapes as for the larger rate constant, but are approximately ten times smaller, again indicating that oxygen consumption is limited entirely by reaction kinetics, not by transport.

The TOUGHREACT and TOUGH2-CHEM simulations agree well for the quasi-stationary states (QSS), but show significant differences during the transient approach to the QSS. This is attributed to the somewhat different process descriptions, with TOUGHREACT neglecting effects of changes in oxygen partial pressure on gas and liquid advection. 


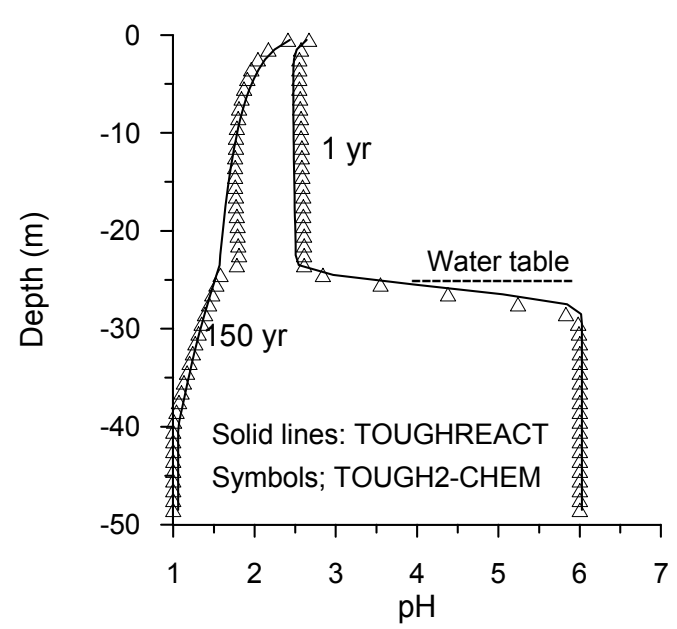

(a)

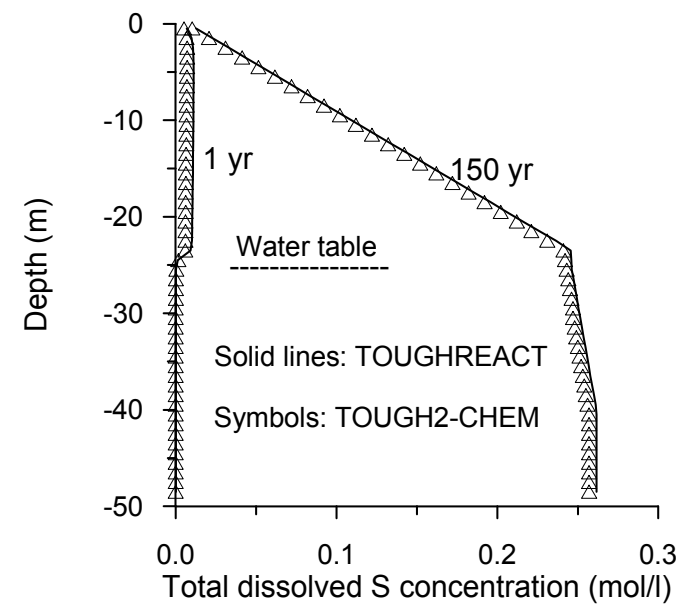

(b)

Figure 9. $\mathrm{pH}$ and total dissolved $\mathrm{S}$ for case 4 (TOUGHREACT) and case 5 (TOUGH2-CHEM), using a kinetic rate constant of $\mathrm{k}=2 \times 10^{-10} \mathrm{~mol} \mathrm{~m}^{-2} \mathrm{~s}^{-1}$. Solid lines: TOUGHREACT results considering oxygen gas diffusion in addition to chemical transport in the liquid phase. Symbols: TOUGH2-CHEM results considering reaction effect on the fluid flow, gas advection and diffusion. 


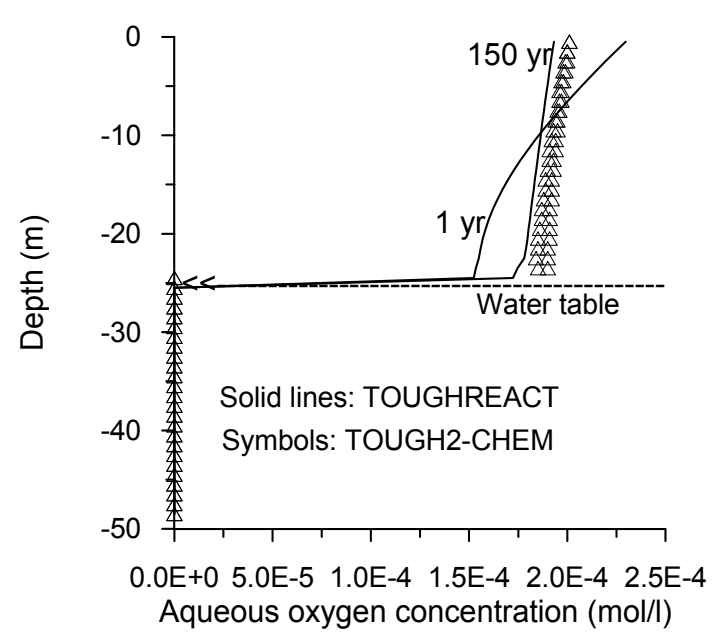

(a)

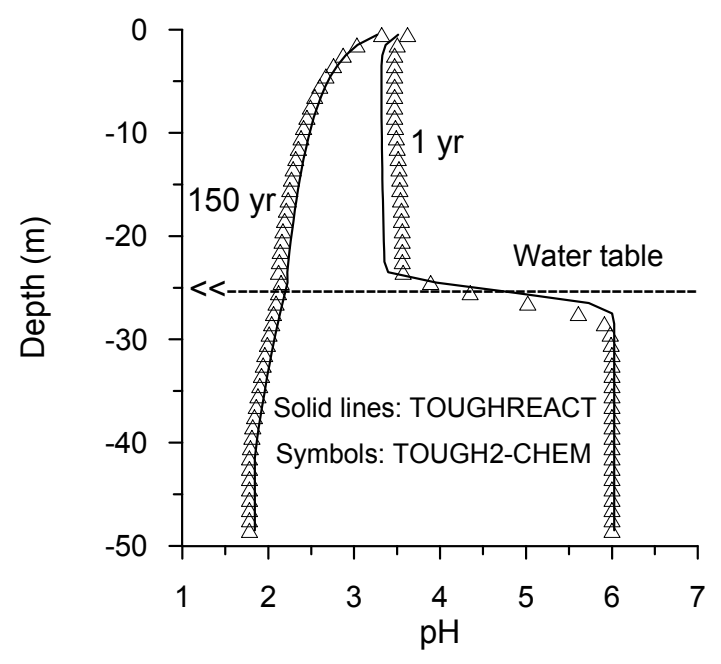

(b)

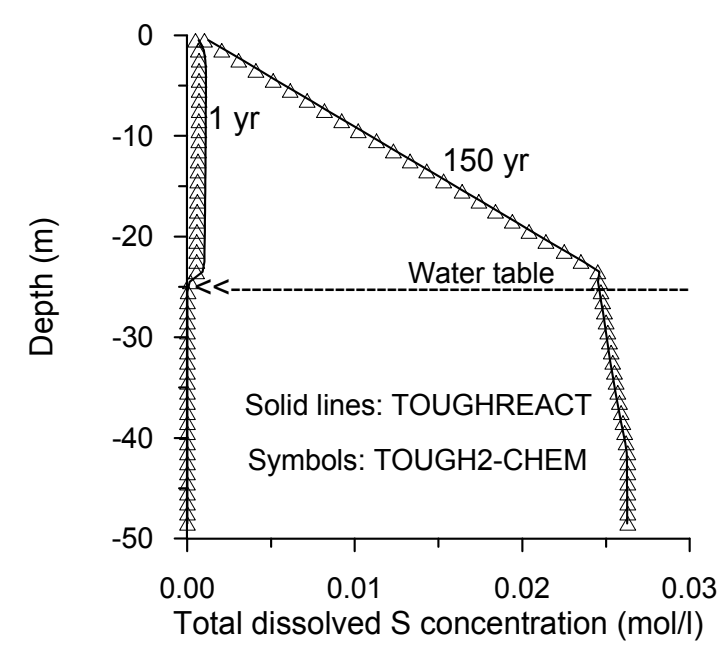

(c)

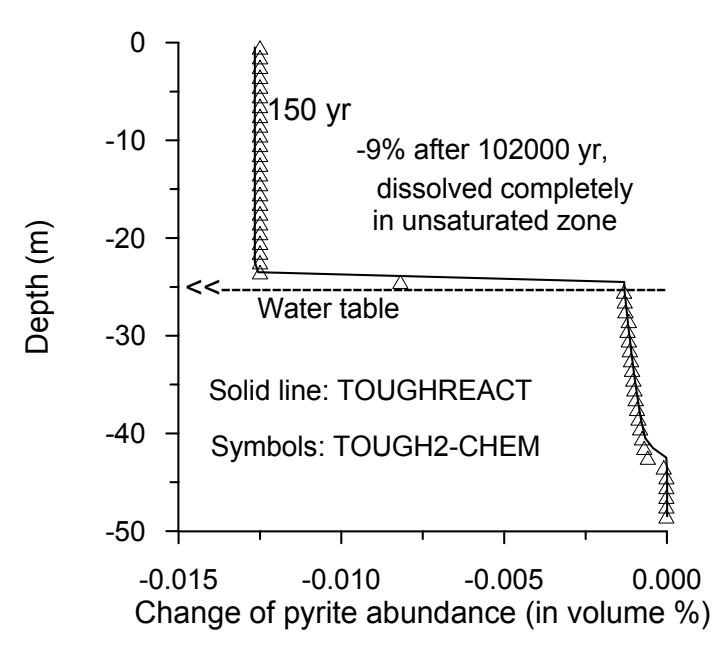

(d)

Figure 10. Aqueous oxygen, $\mathrm{pH}$, total dissolved $\mathrm{S}$ and change of pyrite abundance using a kinetic rate constant of $\mathrm{k}=2 \times 10^{-11} \mathrm{~mol} \mathrm{~m}^{-2} \mathrm{~s}^{-1}$. Solid lines: TOUGHREACT results considering oxygen gas diffusion in addition to chemical transport in the liquid phase. Symbols: TOUGH2CHEM results considering reaction effect on the fluid flow, gas advection and diffusion. 


\section{Discussions}

\subsection{Mass balance error}

The saturated column (case 1) was employed to examine global mass conservation. Three runs were performed with TOUGHREACT using three different time steps: 1, 3 and 6 days. Results from the three runs agree well and are in fact indistinguishable on the scale of Figure 5. However, the mass balance errors are slightly different. TOUGHREACT calculates mass balances for the entire system which can be printed out at user-specified times. A chemical component initially present (aqueous and solid phases) in the system plus that entering the system (called input), should be equal to the component currently present in the system plus that leaving the system (output). A relative error $E_{\mathrm{r}}$, a parameter for measuring this mass balance error, is defined as

$$
\mathrm{E}_{\mathrm{r}}=\left|\frac{(\text { current }+ \text { output })-(\text { initial }+ \text { input })}{\text { initial }+ \text { input }}\right| \times 100 \%
$$

$\mathrm{E}_{\mathrm{r}}$ for $\mathrm{S}$ and $\mathrm{Fe}$ is presented in Figure 11. It can be seen that the error increases as the time step size decreases. This is because a smaller time step requires more computing operations for the same period of simulation. The error for all three runs is linearly increasing with time. Errors for a short simulation period are very small (on the order of $10^{-8}$ ). However, for simulations over geological time the error can become significant. Extrapolating from the data given in Figure 11, for a time step of 1 day the error can reach $1 \%$ after $1.71 \times 10^{6} \mathrm{yr}$. 


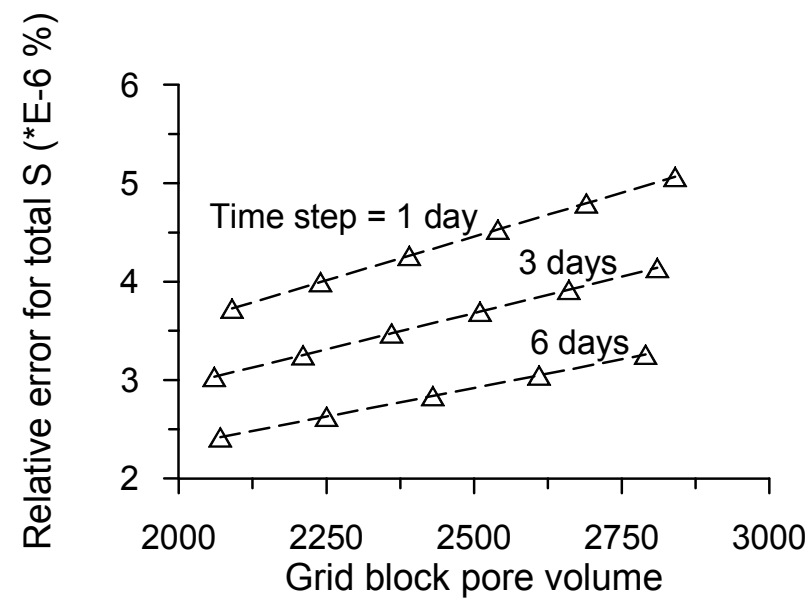

Figure 11. Relative mass balance error $\left(E_{r}\right)$ for total sulfur versus grid block pore volume (equals time in days) with different time steps.

6.2 Advancement of pyrite oxidation front in liquid advection dominant flow systems

From Figure 7, we can see that in the top blocks, free aqueous oxygen concentration decreases linearly (Figure 7a), and total dissolved S increases linearly (Figure 7c). When aqueous oxygen concentration is high, pyrite oxidation is far from the equilibrium state (Ague and Brimhall, 1989). Under these conditions, $\Omega<<1$ in Eq. 4, so that dissolution rate takes on an approximate constant or maximum value, $\mathrm{r}_{\mathrm{m}}=\mathrm{Ak}$ (note that chemical calculation is in terms of $\mathrm{kg} \mathrm{H} \mathrm{H}_{2} \mathrm{O}$ or liter solution if density is $1 \mathrm{~kg} \mathrm{l}^{-1}$ ). For case 3 using a rate constant of $\mathrm{k}=2 \times 10^{-13} \mathrm{~mol}$ $\mathrm{m}^{-2} \mathrm{~s}^{-1}$, the actual rate over the maximum rate $\mathrm{r} / \mathrm{r}_{\mathrm{m}}$ at different times is present in Figure 12 . The pyrite oxidation front moves as the water is moving. Behind the front, pyrite oxidative dissolution has a constant rate. After 20 years the rate distribution remains unchanged. 


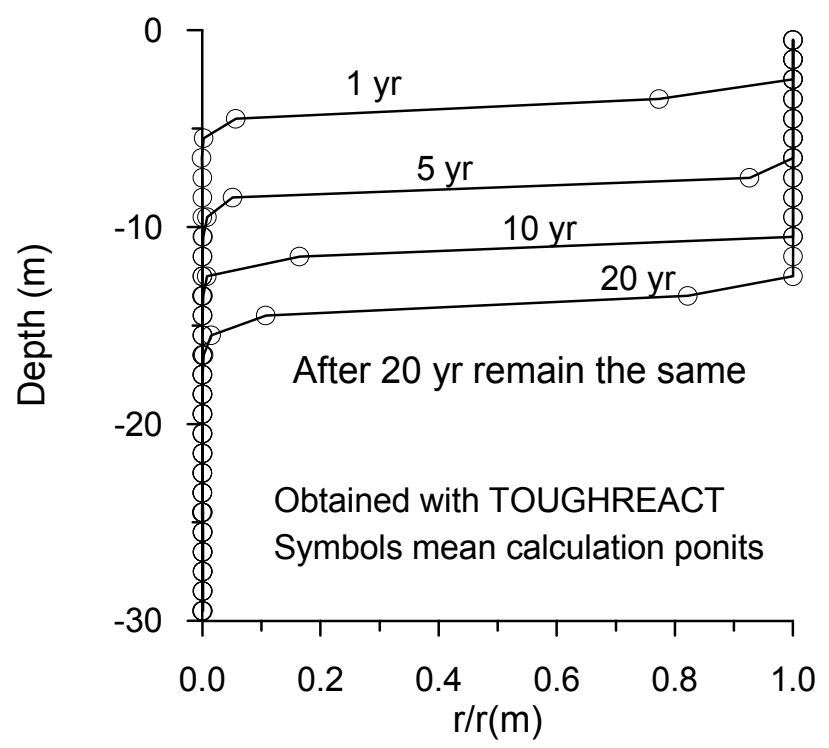

Figure 12 Relative dissolution rate (divided by the maximum rate) distribution at different times for case 3 using a rate constant of $\mathrm{k}=2 \times 10^{-13} \mathrm{~mol} \mathrm{~m}^{-2} \mathrm{~s}^{-1}$.

The depth of the front can be estimated from the oxygen mass balance. We first start with

$$
\int_{0}^{\mathrm{t}} \mathrm{P}_{\mathrm{O} 2}+\int_{0}^{\mathrm{t}} \mathrm{E}_{\mathrm{O} 2}=\int_{0}^{\mathrm{t}} \mathrm{I}_{\mathrm{O} 2}
$$

where $\mathrm{P}_{\mathrm{O} 2}$ is the rate of oxygen consumption by pyrite oxidation in the entire system per unit time (in units of $\mathrm{mol} \mathrm{s}^{-1}$ ), $\mathrm{E}_{\mathrm{O} 2}$ is the rate of oxygen consumption (negative for generation) by all other reactions except pyrite oxidation (including free aqueous oxygen) per unit time, and $\mathrm{I}_{\mathrm{O} 2}$ is the oxygen supply rate by infiltration from the land surface. The distribution of $\mathrm{E}_{\mathrm{O} 2}$ term decreases with time (see Figure 13), and amounts to less than 3\% after a quasi-stationary state is reached. Neglecting $\mathrm{E}_{\mathrm{O} 2}$, we have 


$$
3.5 \cdot 10^{3} \cdot \phi \mathrm{S}_{1} \int_{0}^{\mathrm{z}_{\mathrm{b}}} \mathrm{r}(\mathrm{z}) \mathrm{dz}=\mathrm{I}_{\mathrm{O} 2}
$$

where $\mathrm{z}_{\mathrm{b}}$ is the depth beyond which $\mathrm{r}=0$ (note that dissolution of 1 mole of pyrite requires 3.5

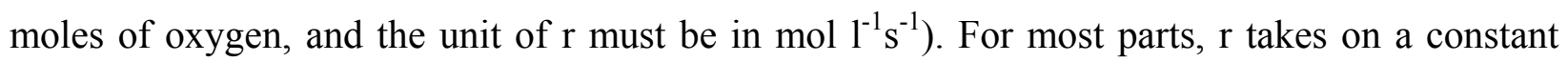
value of $r_{m}$ (see Figure 12), so we have

$$
3.5 \cdot 10^{3} \cdot \phi \mathrm{S}_{1}\left[\mathrm{r}_{\mathrm{m}} \mathrm{z}_{\mathrm{p}}+\int_{\mathrm{z}_{\mathrm{p}}}^{\mathrm{z}_{\mathrm{b}}} \mathrm{r}(\mathrm{z}) \mathrm{dz}\right]=\mathrm{I}_{\mathrm{O} 2}
$$

where $z_{p}$ is the depth of pyrite oxidation with the maximum rate. The second term of Eq. 16 is small (see Figure 12). For estimation purposes, we neglect this term, and then we have

$$
\mathrm{z}_{\mathrm{p}}=\frac{\mathrm{I}_{\mathrm{O}_{2}}}{3500 \phi \mathrm{S}_{1} \mathrm{r}_{\mathrm{m}}}
$$

In the simulations for the unsaturated-saturated flow system, $\mathrm{I}_{\mathrm{O} 2}=5.6126 \times 10^{-10} \mathrm{~mol} \mathrm{~m}^{-2} \mathrm{~s}^{-1}$, $\phi=0.1, \mathrm{~S}_{\mathrm{l}}=0.3$ (unsaturated zone), so $\mathrm{z}_{\mathrm{p}}=5.345 \times 10^{-12} / \mathrm{r}_{\mathrm{m}}$. For different values of the rate constants $k$, the values of $z_{p}$ calculated from Eq. 17 are listed in Table 4. This estimation is confirmed by the computer simulation (see Figure 12). 


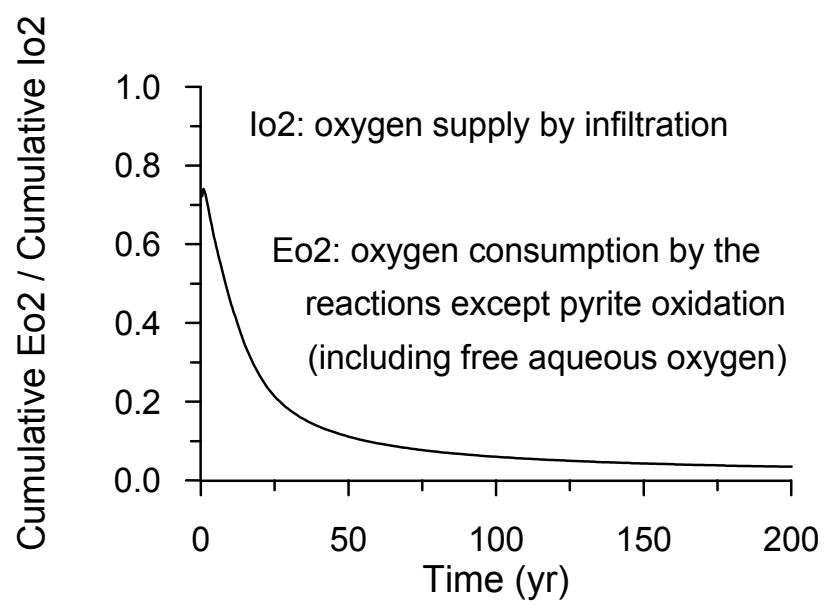

Figure 13. Relative oxygen consumption by reactions except pyrite oxidation (including free aqueous oxygen) versus time for case 3 using a rate constant of $\mathrm{k}=2 \times 10^{-13} \mathrm{~mol} \mathrm{~m}^{-2} \mathrm{~s}^{-1}$.

Table 4. The estimation of the depth $\left(z_{p}\right)$ of pyrite oxidation front having the maximum rate using different kinetic rate constant $\mathrm{k}$.

\begin{tabular}{|c|c|c|}
\hline $\mathrm{k}\left(\right.$ in $\left.\mathrm{mol} \mathrm{m} \mathrm{m}^{-2} \mathrm{~s}^{-1}\right)$ & $\mathrm{r}_{\mathrm{m}}\left(\right.$ in $\left.\mathrm{mol} \mathrm{l}^{-1} \mathrm{~s}^{-1}\right)$ & $\mathrm{z}_{\mathrm{p}}($ in $\mathrm{m})$ \\
\hline $2 \times 10^{-10}$ & $3.91 \times 10^{-10}$ & $1.367 \times 10^{-2}$ \\
\hline $2 \times 10^{-11}$ & $3.91 \times 10^{-11}$ & $1.367 \times 10^{-1}$ \\
\hline $2 \times 10^{-12}$ & $3.91 \times 10^{-12}$ & 1.367 \\
\hline $2 \times 10^{-13}$ & $3.91 \times 10^{-13}$ & 13.67 \\
\hline
\end{tabular}

\subsection{Kinetics over equilibrium}

Whether a particular reaction should be described as governed by the local equilibrium approximation (LEA) or by kinetic rates depends not only on the reaction itself but also on the rates of hydrodynamic processes (Domenico and Schwarz, 1990). A reaction is kinetically controlled when the time required to reach equilibrium is significant in comparison to characteristic times for transport of reactants. In the above simulations for reactive chemical 
transport only in the liquid phase (cases 2 and 3), the choice of equilibrium depends mainly on three factors: (1) kinetic rate, (2) space discretization, and (3) oxygen availability.

At a large rate of $\mathrm{k}=2 \times 10^{-10} \mathrm{~mol} \mathrm{~m}^{-2} \mathrm{~s}^{-1}$ (case 3), the results become indistinguishable from those for equilibrium (case 2). The lower limit for applicability of the LEA is obtained by requiring the depth to the reaction front to be less than the grid spacing, $z_{p} \leq \Delta z$. From Eq. 17, we have

$$
\frac{\mathrm{I}_{\mathrm{O}_{2}}}{3500 \phi \mathrm{S}_{1} \mathrm{r}_{\mathrm{m}}} \leq \Delta \mathrm{z}
$$

For the grid spacing $\Delta \mathrm{z}=1 \mathrm{~m}$ used in our simulations, the LEA is applicable when $\mathrm{r}_{\mathrm{m}} \geq 5.345 \times 10^{-12}$ mol $\mathrm{l}^{-1} \mathrm{~s}^{-1}$ (rate constant $\mathrm{k} \geq 2.734 \times 10^{-12} \mathrm{~mol} \mathrm{~m}^{-2} \mathrm{~s}^{-1}$ ). Note that the constraint for applicability of the LEA becomes more stringent for finer space discretization. If we use a large rate constant of $\mathrm{k}=2 \times 10^{-10} \mathrm{~mol} \mathrm{~m}^{-2} \mathrm{~s}^{-1}\left(\mathrm{r}_{\mathrm{m}}=3.91 \times 10^{-10} \mathrm{~mol}^{-1} \mathrm{~s}^{-1}\right.$, see Table 4$)$, applicability of the LEA requires

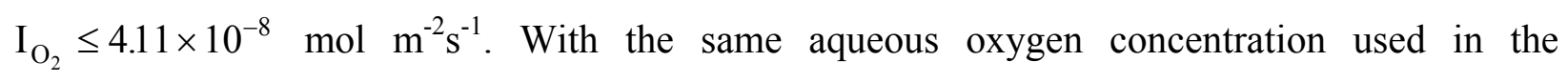
simulations, the infiltration rate limit is $\mathrm{q} \leq 5.126 \mathrm{~m} \mathrm{yr}^{-1}$.

If oxygen transport by gas diffusion processes is considered, the LEA cannot be used. For cases 4 and 5 , the liquid advection time for a grid block is $0.43 \mathrm{yr}$ (157 days), while the gas diffusion time is 1.32 days, so the gas diffusion process is several orders of magnitude faster than the liquid advection.

\subsection{Importance of gaseous oxygen transport}

When oxygen gas transport processes are considered in addition to chemical transport in the liquid phase, a maximum rate of pyrite oxidation is reached very quickly throughout the 
entire unsaturated zone (see the curve after $0.1 \mathrm{yr}$ in Figure 14). In the top of the saturated zone, pyrite is still oxidized by oxygen supply through liquid advection but the rate is much smaller. With the same $\mathrm{k}=2 \times 10^{-10} \mathrm{~mol} \mathrm{~m}^{-2} \mathrm{~s}^{-1}$ and by neglecting oxygen gas transport processes, pyrite oxidation occurs only at the first grid block and the maximum cannot be reached (see Table 4). Much lower $\mathrm{pH}$ and higher dissolved concentrations are obtained by considering gas transport processes. The oxygen gas diffusion process plays a dominant role in the chemical evolution for pyrite oxidation in unsaturated-saturated conditions.

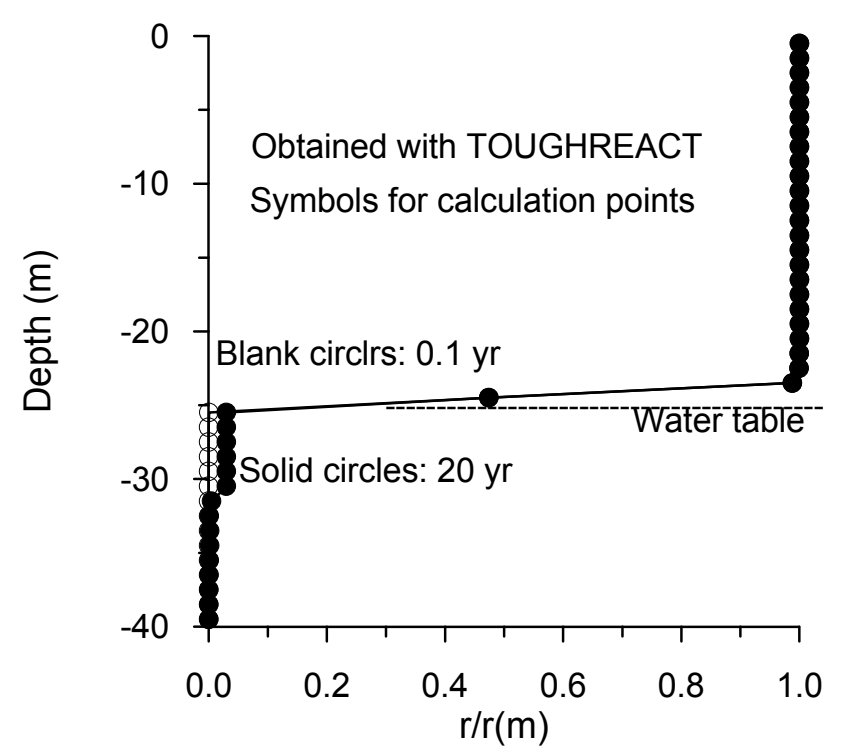

Figure 14. Relative dissolution rate (divided by the maximum rate) distribution at different times for case 4 using a rate constant of $\mathrm{k}=2 \times 10^{-11} \mathrm{~mol} \mathrm{~m}^{-2} \mathrm{~s}^{-1}$.

\subsection{Comparison of the two codes}

For the cases (1,2 and 3) considering only chemical transport in the liquid phase, the results obtained with both codes match very well. If gaseous species transport processes are 
considered in addition to transport in the liquid phase, results are slightly different. TOUGH2CHEM provides a more complete process description, which includes the effects of partial pressure reduction due to reactions on the fluid flow. On the other hand, TOUGHREACT is more efficient than TOUGH2-CHEM (see Table 5). TOUGH2-CHEM solves all flow and multicomponent transport and reaction equations simultaneously. TOUGHREACT solves them sequentially, and transport and reaction iteratively. The transport is solved on a component basis, while the reactions are modeled on a grid block basis. The number of equations solved by the two approaches are summarized in Table 6 . For pyrite oxidation only by rainwater infiltration, we know the steady-state flow distribution but TOUGH2-CHEM still needs to solve the flow. In this condition, TOUGHREACT solves the flow only once at the first time step.

Table 5. CPU times (minutes on a Pentium 200 PC) required by TOUGHREACT and TOUGH2CHEM for the unsaturated-saturated cases (a simulation time of $150 \mathrm{yr}$ ).

\begin{tabular}{lll}
\hline & TOUGHREACT & TOUGH2-CHEM \\
\hline Considering gas transport (cases 4, 5) & 3.0 & 90 \\
No gas transport (case 3) & 1.9 & 15 \\
\hline
\end{tabular}

Table 6. Number of equations per iteration required to be solved simultaneously by TOUGHREACT and TOUGH2-CHEM for the pyrite oxidation problem in the unsaturatedsaturated medium. $\mathrm{N}_{\mathrm{B}}=$ number of grid blocks (50), $\mathrm{N}_{\mathrm{C}}=$ number of chemical components (5), and $\mathrm{N}_{\mathrm{S}}=$ number of chemical species (13).

\begin{tabular}{lll}
\hline Approach & Number of equations \\
\hline TOUGHREACT & Flow (EOS3): $3 \times \mathrm{N}_{\mathrm{B}}=150 \quad$ for one time \\
& Transport: $\mathrm{N}_{\mathrm{B}}=50 \quad$ for $\mathrm{N}_{\mathrm{C}}=5$ times \\
& Reaction: $\mathrm{N}_{\mathrm{C}}+1$ (pyrite) for $\mathrm{N}_{\mathrm{B}}=50$ times \\
TOUGH2-CHEM & Flow+transport+reaction \\
\hline
\end{tabular}




\section{Conclusions}

Oxidative weathering of pyrite, as well as of other metal sulfides, is an extremely difficult process to model numerically because (1) it is driven by oxygen, whose concentration in ambient soil gas and dissolved in pore water in the unsaturated zone, is very small, so that of the order of $10^{5}$ pore volumes of fluid are required to consume 1 vol.- $\%$ of solid mineral; (2) the chemical activities and total elemental solubilities of key species vary over an enormous range of tens of orders of magnitude during redox processes; and (3) the oxidation involves several reaction steps that are partly kinetically controlled, and catalyzed by microbial acitivity.

This paper has presented the formulation of a general multi-phase advective-diffusive reactive transport model for redox processes. Two alternative numerical implementations were developed, using either a sequential iteration approach for transport and reactions, or a fullycoupled simultaneous solution. Simulations of a fully and a variably-saturated pyrite oxidation problem showed reasonable geochemical behavior, and satisfactory agreement between the two approaches. In the unsaturated zone, gas diffusion was found to be the dominant mechanism for oxygen supply.

The fully-coupled solution approach allows larger time steps, but the numerical work per time step is also larger. For the problem considered in this study, time steps had to be limited to resolve adequately highly transient changes, and the sequential iteration approach was found to be more efficient numerically. The relative efficiency of different approaches appears to be highly problem dependent. 


\section{Acknowledgement}

The authors appreciate stimulating discussions with John Apps, Eric Sonnenthal, Nicolas Spycher, and Frederic Gérard. We are grateful to Curtis Oldenburg and Ardyth Simmons for a review of the manuscript and suggestions for improvement. This work was supported by the Laboratory Directed Research and Development Program of the Ernest Orlando Lawrence Berkeley National Laboratory, under Contract No. DE-AC03-76SF00098 with the U.S. Department of Energy and by Marsden Fund grant WEIR IRL 601.

\section{Notation}

$\begin{array}{ll}\text { a } & \text { air index (subscript) } \\ \text { A } & \text { specific reactive surface area, } \mathrm{m}^{2} \mathrm{~m}^{-3} \\ \mathrm{c} & \text { concentration of chemical species, } \mathrm{mol}^{-1} . \\ \mathrm{C} & \text { concentration of component, } \mathrm{mol}^{-1} . \\ \mathrm{D}_{\beta} & \text { molecular diffusion coefficient in phase } \beta \text { (l and } \mathrm{g} \text { ). } \\ \mathrm{g} & \text { gas phase index (subscript) } \\ \mathrm{g} & \text { gravitational acceleration vector, } \mathrm{m} \mathrm{s}^{-2} \\ \mathrm{H} & \text { heat index (subscript) } \\ \mathrm{h}_{\beta} & \text { specific enthalpy of phase } \beta(1 \mathrm{and} \mathrm{g}), \mathrm{J} \mathrm{kg}^{-1} . \\ \mathrm{j} & \text { chemical component index (subscript or superscript). } \\ \mathrm{k} & \text { time step number. } \\ \mathrm{k} & \text { medium permeability, } \mathrm{m}^{2} . \\ \mathrm{k}_{\mathrm{m}} & \text { Mineral dissolution rate constant, } \mathrm{mol} \mathrm{m}^{-2} \mathrm{~s}^{-1} \\ \mathrm{~K}_{\mathrm{r} \beta} & \text { relative permeability of phase } \beta(1 \mathrm{and} \mathrm{g}) . \\ \mathrm{K} & \text { Thermodynamic equilibrium constant. } \\ \mathrm{l} & \text { liquid phase index (subscript). } \\ \mathrm{N}_{1} & \text { number of aqueous components } \\ \mathrm{N}_{\mathrm{g}} & \text { number of gaseous components. }\end{array}$




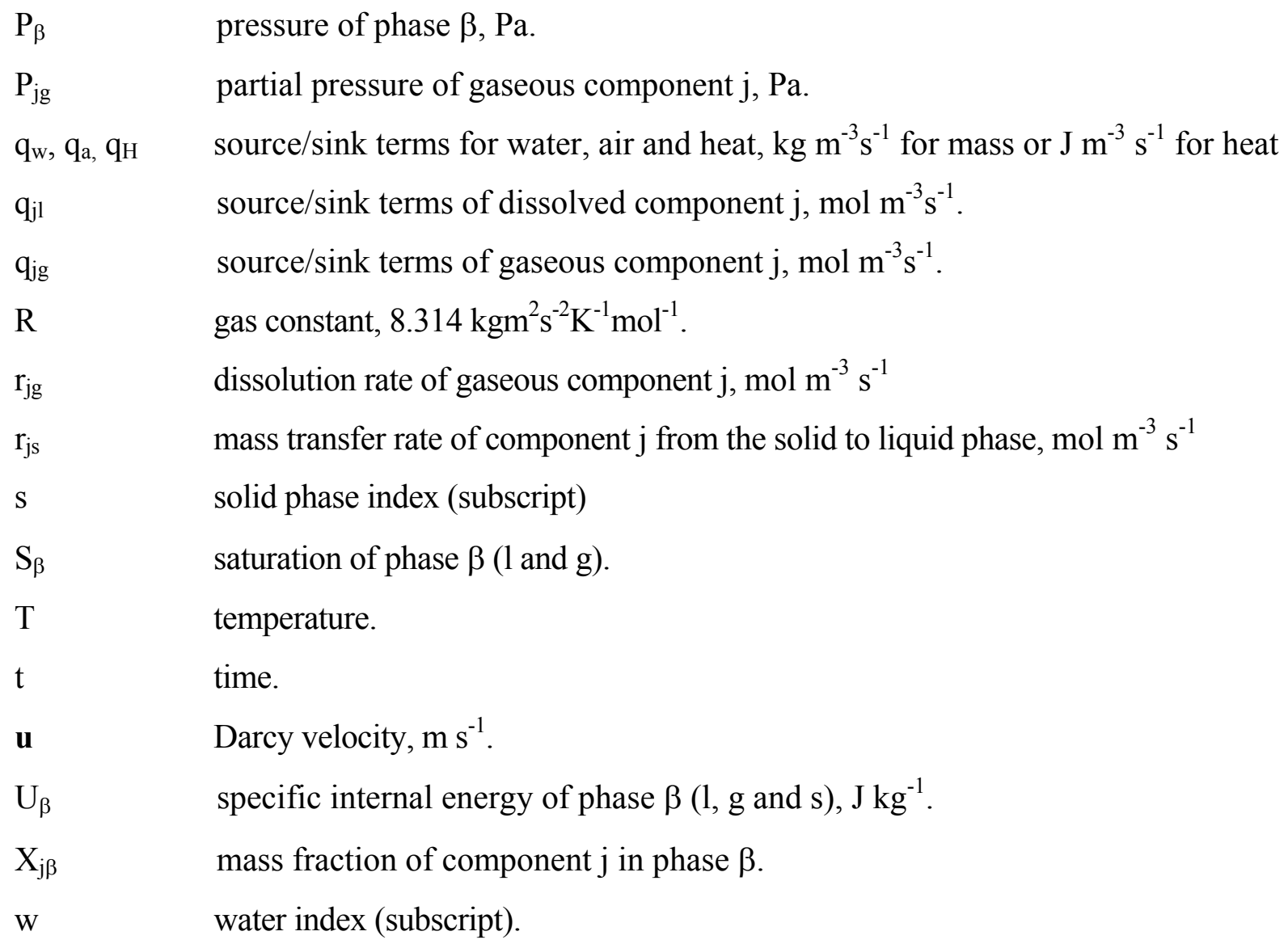

\section{References}


Ague, J. J., and Brimhall G. H., 1989, Geochemical modeling of steady state and chemical reaction during supergene enrichment of porphyry copper deposits, Econ. Geol., 84, 506-528.

Brown, A.D., and J.J. Jurinak, 1989, Mechanisms of pyrite oxidation in aqueous mixtures, Journal of Environmental Quality, v. 18, pp. 545-550.

Domenico, P. A., and F. W., Schwarzt, 1990, Physical and Chemical Hydrogeology, John Wiley and Sons, New York, 824 pp.

Kleinmann R.L.P, Crerar, D.A., Pacelli, R.R., 1981, Biogeochemistry of acid mine drainage and a method to control acid formation. Mining Eng., March, pp 300-500.

Lasaga, A. C., J. M. Soler, J. Ganor, T.E. Burch, and K. L. Nagy, 1994, Chemical weathering rate laws and global geochemical cycles, Geochim. Cosmochim. Acta, 58, 2361-2386.

Lefebvre, R., 1995, Modeling Acid Mine Drainage in Waste Rock Dumps, in K. Pruess (editor). Proceedings of the TOUGH Workshop '95, Report LBL-37200, Lawrence Berkeley Laboratory, Berkeley, California.

Lefebvre, R., J. Smolensky, and D. Hockley, 1998, Modeling of Acid Mine Drainage Physical Processes in the Nordhalde of the Ronneburg Mining District, Germany, Proceedings of the TOUGH Workshop '98, Lawrence Berkeley Laboratory Report LBNL-41995, Berkeley, California.

Lichtner, P.C., 1988, The Quasi-Stationary State Approximation to Coupled Mass Transport and Fluid-Rock Interaction in a Porous Medium, Geochim. Cosmochim. Acta, Vol. 52, pp. 143 165.

Lichtner, P. C., 1996, Continuum formulation of multicomponent-multiphase reactive transport, In: Reactive transport in porous media, Reviews in Mineralogy, Vol. 34, 1-79, Mine. Soc. Am.

Lowson, R.T. 1982, Aqueous oxidation of pyrite by molecular oxygen. Chemical Reviews, v 82, pp 461-497.

McKibben, M.A., and H.L. Barnes, 1986, Oxidation of pyrite in low temperature acidic solutions-Rate laws and surface textures: Geochem. et Cosmo. Acta, v 50 pp 1509-1520.

Narasimhan, T. N. and P. A. Witherspoon, 1976, An Integrated Finite Difference Method for Analyzing Fluid Flow in Porous Media, Water Res. Res., 12 (1), 57-64. 
Nicholson, R.V., 1994, Iron-sulfide oxidation mechanisms - laboratory studies, in Jambor, J.L., and Blowes, D.W. (eds.), The Environmental Geochemistry of Sulfide Mineral-Wastes: Mineralogical association of Canada, Short Course Handbook, v. 22, pp. 736-741.

Nordstrom, D.K., C.N. Alpers, 1997, The Environmental Geochemistry of Mineral Deposits. Part A. Processes, Methods and Health Issues. (Plumlee, G.S., Logsdon, M.J. (Eds) ), Reviews in Economic Geology, v 6, Society of Economic Geologists.

Nordstrom, D.K. 1982, Aqueous pyrite oxidation and the consequent formation of secondary iron minerals, in Acid Sulfate Weathering (Kittrick, J.A., Fanning, D.S., and Hossner, L.R. (eds)). Soil Science Society of America Spec. Pub. No. 10, pp 37-56.

Olson, G.J. 1991, Rate of pyrite bioleaching by Thiobacillus ferrooxidans - Results of an interlaboratory comparison. Applied and Environmental Microbiology, v 57, pp. 642-644.

Pruess, K., TOUGH user's guide, 1987, Nuclear Regulatory Commission, report NUREG/CR-4645 (also Lawrence Berkeley Laboratory Report LBL-20700, Berkeley, California, USA).

Pruess, K., 1991, TOUGH2: A general numerical simulator for multiphase fluid and heat flow, Lawrence Berkeley Laboratory Report LBL-29400, Berkeley, California, USA.

Simunek, J., and D. L. Suares, 1994, Two-dimensional transport model for variably saturated porous media with major ion chemistry, Water Resour. Res., 30(4), 1115-1133.

Singer, P.C., and Stumm, W. 1968, Kinetics of oxidation of ferrous iron, $2^{\text {nd }}$ symposium on Coal Mine Drainage Research: National Coal Association/Bituminous Coal Research, pp 12-34.

Singer, P.C., and Stumm, W. 1970: Acid mine drainage - The rate determining step. Science, v. 167 pp1121-1123.

Steefel, C.I. and A.C. Lasaga, 1994, A coupled model for transport of multiple chemical species and kinetic precipitation/dissolution reactions with applications to reactive flow in single phase hydrothermal system, Am. J. Sci., 294, 529-592.

Walter, A. L., E. O. Frind, D. W. Blowes, C. J. Ptacek, and J. W. Molson, 1994, Modeling of multicomponent reactive transport in groundwater, 2, Metal mobility in aquifers impacted by acidic mine tailings discharge, Water Resour. Res., 30 (11), 3149-3158.

Welch, V.S. II, M.W. Dann, and B. Mehta, 1990, Predicting Oxygen Depletion in Reservoir Environments. Society of Petroleum Engineers paper SPE 20721.

White, S.P., 1995, Multiphase Non-Isothermal Transport of Systems of Reacting Chemicals, Water Resour. Res., Vol. 32, No. 7, pp. 1761-1772. 
Wolery, T. J., EQ3/6, a software package for geochemical modeling of aqueous systems: Package overview and installation guide (version 7.0), Lawrence Livermore Lab., Report UCRL-MA110662 PT I, 1992.

Wunderly, M. D., D. W. Blowes, E. O. Frind, and C. J. Ptacek, 1996, Sulfide mineral oxidation and subsequent reactive transport of oxidation products in mine tailings impoundments: A numerical model, Water Resour. Res., 32 (10), 3173-3187.

Xu, T., F. Gerard, K. Pruess and G. Brimhall. 1997, Modeling Non-Isothermal, Multiphase, Multi-Species Reactive Chemical Transport in Geologic Media, Lawrence Berkeley National Laboratory Report LBNL-40504, Berkeley, California, USA.

Xu, T., K. Pruess and G. Brimhall, 1998a, An improved equilibrium-kinetics speciation algorithm for redox reaction in variably saturated flow system, Lawrence Berkeley National Laboratory Report LBNL-41789, also submitted to Computer \& Geosciences.

Yeh, G. T., and V. S. Tripathi, 1991. A model for simulating transport of reactive multispecies components: model development and demonstration, Water Resour. Res. 27(12), 3075-3094.

Zysset, A., F. Stauffer and T. Dracos, 1994, Modeling of chemically reactive groundwater transport, Water Resour. Res., 30 (7), 2217-2228. 